\title{
Demographic Changes and the Labor Income Share
}

\author{
Hippolyte d'Albis* Ekrame Boubtane ${ }^{\dagger}$ Dramane Coulibaly ${ }^{\ddagger}$
}

November 20, 2020

\begin{abstract}
In this article, we study the impact of demographic changes on the inequality between capital and labor incomes. More precisely, we analyze the impact of exogenous changes in both the rate of natural increase and the net migration rate on labor income as a share of total income. We estimate a structural vector autoregression (VAR) model on a panel of 18 OECD countries with annual data for 1985-2018. We find that the response of the labor income share to an exogenous change in the rate of natural increase is significantly negative a few years after the shock, whereas its response to an exogenous change in the net migration rate is significantly positive. This suggests that in addition to the factors usually introduced in the literature, demographic factors play a role in the observed variation in the labor income share.
\end{abstract}

JEL classification: E20, F22, J61.

Keywords: International Migration; Natural Increase, Labor Income Share.

${ }^{*}$ Paris School of Economics, CNRS, F-75014, Paris, France. Corresponding author, E-mail: hdalbis@psemail.eu

${ }^{\dagger}$ Université Clermont Auvergne, CNRS, IRD, CERDI, F-63000 Clermont-Ferrand, France.

‡Univ Lyon, Université Lumière Lyon 2, GATE UMR 5824, F-69130 Ecully, France. 


\section{Introduction}

In many developed countries, natural increase (difference between numbers of births and deaths) was for many years greater than net migration (difference between immigration and emigration). This has changed since the end of the 1990s. Figure 1-(a) shows that, on average, migration accounted for most of the population growth in OECD countries over the last twenty years. There are, of course, differences between countries, but Figure 1(b), showing the percentage of these countries where net migration is higher than natural increase, clearly demonstrates that this trend is upward.

In public and political discussions, international migration is often associated with other demographic variables. Some people, for example, think that migration may be a natural or necessary response to population aging. Others think that migration must be reduced and fertility increased. Meanwhile, in academic economics publications, demographic variables are usually analyzed separately or, as in the textbook growth model, combined in a single variable: population growth rate. This article proposes a unified analysis of the empirical and theoretical effects of natural increase and net migration rates on incomes and inequalities. This is relevant, as any increase in inequality may reinforce the opposition to globalization in general and international migration in particular. We focus here on the inequality between capital and labor incomes, where the relationship with demography has been less well researched ${ }^{1}$ despite the quality of the available data. Moreover, we show that variation in this inequality correlates with disparity between the income of the richest and poorest because capital is more concentrated in corporate profits, which are less equally distributed than wages.

Natural increase and net migration have one point in common: any increase causes an increase in population, which may lead to a dilution of capital if returns to scale in production are constant. However, the two components of population growth differ widely in their effects on population age structure: a rise in natural increase (via more births or

\footnotetext{
${ }^{1}$ The literature has focused on the relationship between population structure and the disparity in income distribution among the population (Lam, 1986, 1987) and on the effect of immigration on wage inequalities among native workers (Borjas et al., 1997; Lerman, 1999; Card, 2009; Dustmann et al., 2013; Edo and Toubal, 2015).
} 
fewer deaths) increases the number of dependents, whereas a rise in migration increases the number of working-age people. An increase in the share of the latter in population has a favorable effect on economic growth (Aksoy et al., 2019), and thus international migration is likely to produce a demographic dividend (d'Albis et al., 2019). However, productivity is affected by this increase in the number of workers, which may affect wages. The ultimate effect on labor income as a share of total income is thus a priori an ambivalent one and depends on the extent of the response of the capital to labor ratio to demographic shocks.

We empirically examine the effects of natural increase and net migration rates on per capita labor and capital incomes and on labor income share. We estimate a VAR model for a panel of 18 OECD countries from 1985 to 2018. This methodology helps to control for endogeneity between demographic and economic variables and has been used to examine the economic effects of international migration (d'Albis et al., 2018, 2019; Furlanetto and Robstad, 2019) and the effects of the economy on birth and death rates (Eckstein et al., 1985; Nicolini, 2007; Fernihough, 2013). It has been used to analyze the determinants of the labor income share (Kim, 2016; Bergholt et al., 2019). We find that the labor income share falls some years after a natural increase shock but rises after a migration shock. This suggests that in addition to the factors usually introduced in the literature, ${ }^{2}$ demographic factors play a role in the observed variation in the labor income share. Although quantitatively probably smaller, their effect tends to counter economic factors because of the rise in migration and fall in natural increase have had a mainly stabilizing effect on the labor income share. Our empirical findings are shown to be consistent with a simple neoclassical framework provided that the elasticity of substitution between capital and labor is less than 1 , which is likely to be verified empirically.

The article is structured as follows. Section 2 presents our identification strategy. Section 3 presents our main results and discuss them. Section 4 extend the analysis to

\footnotetext{
${ }^{2}$ Product and labor market regulations (Blanchard and Giavazzi, 2003), globalization (Böckerman and Maliranta, 2012; Elsby et al., 2013; Reshef and Santoni, 2019), capital biased technology growth (Karabarbounis and Neiman, 2014), technology (Autor et al., 2020; Aghion et al., 2019) and most notably automation (Acemoglu and Restrepo, 2018a,b; Bergholt et al., 2019; Basso and Jimeno, 2020) and variations in competition (Gutiérrez and Philippon, 2019; Philippon, 2019).
} 
provide some robustness checks and additional results. Section 5 concludes.

\section{Empirical strategy}

\section{$2.1 \quad$ Data}

Our sample includes yearly observations from 1985 to 2018 for 18 OECD countries: Australia, Austria, Belgium, Canada, Denmark, Finland, France, Germany, Ireland, Italy, Japan, the Netherlands, Norway, Portugal, Spain, Sweden, the United Kingdom and the United States. Data are obtained from Eurostat (2020) and OECD (2017, 2018, 2020a) databases.

The two main economic variables we use are labor and capital incomes. Labor income is calculated by including the compensation of employees, which consists of wages and employers' social contributions. Capital income is evaluated using the gross operating surplus and gross mixed income. This measure includes paid or received interest, rents or charges on financial or tangible non-produced assets. These variables are used in real terms (computed using the GDP deflator) and are expressed in per capita terms using the annual average population. The sum of labor and capital incomes is called the total income, which corresponds to GDP minus taxes less subsidies on production and imports, namely the incomes generated within the country and used to remunerate the production factors (see UN et al., 2009, for more details). Since taxes and subsidies could be used for a variety of purposes, the literature usually does not consider them when exploring the labor income share (see Laurence, 2015, for more details). We compute the labor income share as labor income divided by total income. In Appendix A.1, these variables are precisely defined and some additional variables are presented.

We also use the two components of population growth: natural increase and net migration. The natural increase is given by the difference between the number of live births and the number of deaths occurring in a year. Net migration is given by the difference between the population growth, the difference between the size of the population at the end and the beginning of a year, and the natural increase. Net migration then accounts 
for the difference between immigration into and emigration out of the country during the year. Note that all national statistical offices produce statistics on net migration in order to produce estimates of the total resident population. They use various sources to estimate inflows (immigration) and outflows (emigration). Net migration data are thus produced on a regular basis since a long time in all countries we consider. This is not necessarily the case for inflows and outflows in general. Moreover, as net migration flows are obtained by subtracting outflows from inflows, differences between countries with respect to the duration of the minimum presence in, or absence from, the host country in order for a migration flow to be counted, tend to be "netted out". In other words, measures of net migration tend to be more comparable across countries, which is not the case for measures of inflows and outflows. ${ }^{3}$ Thus, we use it to measure the net flow of migrants. All the demographic variables are expressed in thousand of inhabitants by using the population on 1 January. Figure 2 displays the evolution of natural increase and net migration over time for each country under consideration. This figure shows important cross-country differences for the two sources of population growth and considerable variations over time. Some descriptive statistics are presented in Appendix A.2.

\subsection{The model}

Our empirical strategy relies on a structural VAR model that has been used to evaluate the economic responses of birth and death rates in Eckstein et al. (1985), Nicolini (2007) and Fernihough (2013). For most countries, accurate economic and demographic data is available annually over a limited time period. Thus, following d'Albis et al. (2019), we consider a panel framework that allows for an accurate analysis based on annual data over the period 1985-2018. We consider the following panel VAR specification:

$$
X_{i t}=\sum_{s=1}^{p} \Gamma_{s} X_{i t-s}+v_{i}+d_{i} t+f_{t}+\varepsilon_{i t} \quad i=1, \ldots, N \text { and } t=1, \ldots, T
$$

\footnotetext{
${ }^{3}$ See Lemaître et al. (2007) for more details. Harmonized data on international migration inflows and outflows produced by the OECD are only available since 2007 (except for the outflows of Canada, France, Portugal, and the United States, which are missing).
} 
where $X_{i t}=\left(x_{i t}^{1}, \ldots, x_{i t}^{m}\right)^{\prime}$ is a $m$-dimensional vector of endogenous variables, the $\Gamma_{s}$ are fixed $(m \times m)$ coefficient matrices, $v_{i}=\left(v_{i}^{1}, \ldots, v_{i}^{m}\right)^{\prime}$ is a vector of country fixed-effects, $d_{i} t=\left(d_{i}^{1}, \ldots, d_{i}^{m}\right)^{\prime} . t$ represent country-specific time (linear) trends, $f_{t}=\left(f_{t}^{1}, \ldots, f_{t}^{m}\right)^{\prime}$ is a common time (year)-specific effect, and $\varepsilon_{i t}=\left(\varepsilon_{i t}^{1}, \ldots, \varepsilon_{i t}^{m}\right)^{\prime}$ is a $m$-dimensional vector of errors that are assumed to satisfy $E\left(\varepsilon_{i t}\right)=0$ and $E\left(\varepsilon_{i t} \varepsilon_{i s}^{\prime}\right)=\Sigma . \mathbb{1}\{t=s\}$ for all $i$ and $t$.

We address the possible heterogeneity in our panel data by using a rather homogenous sample of OECD countries, and by introducing country-fixed effects $v_{i}$ and countryspecific time trends $d_{i} t$. Moreover, to account for cross-country contemporaneous interdependence, we include year-specific effects $f_{t}$, as in d'Albis et al. (2019) .

Given the sizes of the cross-sectional dimension $N$ and the time dimension $T$ of our panel data $(N=18$ and $T=34)$, to remove the short- $T$ dynamic panel data bias or the so-called Nickell (1981) bias, we employ the bias-corrected fixed-effects estimator developed by Hahn and Kuersteiner (2002). For example, Juessen and Linnemann (2012) applied this bias-correction in panel VAR frameworks.

Based on Akaike information criterion (AIC) and Bayesian information criterion (BIC), we set the VAR order $p$ to 2 so as to remove any serial correlation in the errors. Using lag lengths greater than 2 does not change our finding. Preliminary diagnostics (panel unit root tests) reject the null hypothesis of unit root for the detrended variables (with a country-specific linear trend). Our VAR model then considers variables in log levels while controlling for country heterogeneity (by introducing country-specific effects and country-specific time trends) and cross-country interdependence (by introducing year-specific effects).

\subsection{Main specification and identification strategy}

Our aim is to empirically investigate how natural increase and migration shocks influence the labor income share. For this purpose, we consider the following system, which includes its constituent variables, namely capital and labor incomes:

$$
X_{i t}^{1}=\left[\log \left(1+m_{i t}\right), \log \left(1+n_{i t}\right), \log \left(w_{i t}\right), \log \left(r_{i t}\right)\right]^{\prime}
$$


where $m_{i t}$ is the net migration as a share of the population on January $1, n_{i t}$ is the natural increase as a share of the population on January 1, $w_{i t}$ is the labor income per capita, and $r_{i t}$ is the capital income per capita. Because net migration and natural increase rates can be negative, we add one to express these variables in logarithms.

After estimating the VAR coefficients, we conduct structural analysis to identify the vector of structural shocks $\eta_{i t}$ computed as follows: $\eta_{i t}=A \varepsilon_{i t}$, where $A$ is an $m \times m$ matrix such that $E\left(\eta_{i t} \eta_{i t}^{\prime}\right)=I_{m}$ or $A A^{\prime}=\Sigma$. Our identification strategy is based on Cholesky decomposition by setting $A$ as the unique lower-triangular Cholesky factor of $\Sigma$. This decomposition relies on the assumption that variables ordered first in the VAR can affect the other variables contemporaneously, whereas variables ordered later can affect those ordered first only with lags.

Net migration is ordered first since it can contemporaneously affect natural increase (through births) and the economic performances of the host country and it is assumed to respond to them only with a lag. This identifying assumption is justified by the international migration process in which the decision to settle abroad, for at least one year is planned well in advance (d'Albis et al., 2019). In addition to their personal plans, most non-nationals need an administrative permit to settle abroad and the process for obtaining the first residence permit can be long and complex (Smith and Thoenissen, 2019). Finally, the data we use to measure the net flow of permanent migrants concerns persons recorded as residents in the host country, which is sometimes counted with a delay. Indeed, net migration data is produced by national statistical institutes for use in producing current estimates of the total resident population. The natural increase is ordered second and income variables are ordered last, which means that natural increase may contemporaneously impact the economy and respond to it with lag. We follow Nicolini (2007), who justify this assumption by the fact that the endogenous responses of fertility are usually delayed by the waiting times for conception and pregnancy. Although our ordering assumptions are plausible, we are aware that they are crucial and we therefore provide various robustness checks by considering, first, the issues related to anticipations and, second, an alternative identification method based on sign restrictions. 
Finally, our ordering puts labor income before capital income. It is worth noting that, since demographic variables are ordered first in the identification scheme, the order between the other variables (labor income and capital income) does not matter for the analysis of the responses to demographic shocks.

From the estimation results of the baseline specification, the response of the labor income share, defined as $w_{t} /\left(w_{t}+r_{t}\right)$, is computed as follows:

$$
\left.\frac{w}{w+r}\left(\widehat{\log \left(w_{t}\right)}-\log \widehat{\left(w_{t}+\right.} r_{t}\right)\right)
$$

where $\widehat{\log \left(w_{t}\right)}$ is the impulse response of the logarithm of labor income per capita and

$\log \left(\widehat{w_{t}+} r_{t}\right)$ is the one of the logarithm of the sum of total income per capita. ${ }^{4}$ The ratio $w /(w+r)$ is approximated by the overall sample mean and is here equal to 0.545 (see Table A-1). Note that the response of the labor income share is expressed in percentage-point change.

\section{Main empirical results}

We analyze the impact of demographic shocks on the labor share by, first presenting the impulse response functions and, then, discussing them in a simple neoclassical framework.

\subsection{Impulse response functions}

The size of each demographic shock was set to one person per thousand inhabitants. The estimates of the impulse responses are shown in Figure 3 (for some specific periods).

[Figure 3]

We first notice that natural increase monotonically responds to its own shock; the increase remains significant for approximately eight years. Since this shock induces an increase in the total population, it leads to a significant decrease in the net migration rate from two years to at least ten years after the shock. Second, the migration shock has

\footnotetext{
${ }^{4}$ We obtain it by using: $\left.\log \widehat{\left(w_{t}+\right.} r_{t}\right)=\frac{w}{w+r} \widehat{\log \left(w_{t}\right)}+\frac{r}{w+r} \widehat{\log \left(r_{t}\right)}$.
} 
a significant positive effect on the natural population change from the year of the shock until at least ten years after the shock.

Concerning the economic effects, we observe that a natural increase shock leads to a significant decrease in labor income per capita from three years after the shock and until fifteen years after the shock, by 1.38 percent after three years, and by 1.90 percent at the peak (after six years). In response to a natural increase shock, total income per capita decreases significantly from three to eleven years after the shock, by 1.30 percent after three years, and by 1.61 percent at the peak (after five years). Consequently, in response to a natural increase shock, labor income share does not respond significantly during the eight years and decreases significantly from nine years to eighteen years after the shock, by 0.27 percent at the peak (after ten years). On the contrary, migration shocks lead to an immediately significant increase in labor income and total income. Labor income per capita rises significantly by 0.32 percent on impact and by 0.36 percent at the peak (two years after the shock); total income rises significantly by 0.35 percent upon impact and by 0.36 percent at the peak (one year after). As a result, in response to a migration shock, the labor income share rises significantly from the third to the ninth year after the shock, by 0.11 percentage point at the peak (five years after).

The forecast error variance decomposition analysis reported in Table 1 represents the percentage contribution of migration and natural increase shocks to the forecast error variance at horizon $h$, where the $h$ year-ahead forecast error of a given variable is defined as the difference between its actual value and its forecast at horizon $h$ from equation (1). Table 1 first indicates that fluctuations in demographic variables are mainly affected by demographic shocks. At the one-year horizon, the percentage of fluctuations in natural increase due to its own shock and to migration shock are 95.33 and 3.97 percent, respectively. Over fifteen years, these percentages are 61.56 and 18.12 percent, respectively. The contribution of migration shock to migration fluctuations is 99.71 percent at one-year horizon and 84.73 percent at the fifteen years horizon. The contribution of demographic shocks to fluctuations in income variables is low in the short run and increases at long horizons. At the one-year horizon, the percentage of variations in labor income 
due to natural increase shock and migration shock is 0.87 and 3.97 percent, respectively. At the fifteen year horizon, these values increase to 7.20 and 8.41 percent, respectively. Concerning total income per capita, the contribution of the natural increase shock is 1.08 percent at one-year horizon and 5.54 percent at the fifteen year horizon ; the contribution of the migration shock is 6.00 percent at one year and 7.63 percent at the fifteen year horizon. As a result, over fifteen years, the percentages of variation in labor share income due to shocks on natural increase and migration are 1.31 and 5.24 percent, respectively.

\section{[Table 1]}

It is interesting to note that the two sources of population growth have opposite short-run effects on labor income per capita and on total income per capita. Our findings are consistent with previous empirical studies on the impact of demography on the economy. Similar conclusions, on the positive economic effects of international migration were reached by Clemens (2011), Ortega and Peri (2014), Boubtane et al. (2016), and Furlanetto and Robstad (2019), for example. With regard to the literature on the effect of demography on economic performance (see Bloom et al., 2001 for a survey), our results are also consistent. For instance, Bloom and Williamson (1998) discussed the influence of population growth on economic growth and showed that an increase in the share of the working-age population has a positive effect on GDP per capita in a sample including the OECD countries. This finding was confirmed with a VAR estimation by a recent article (Aksoy et al., 2019). As international migration increases the share of the workforce in OECD countries (because migrants are young adults), it can induce a demographic dividend of economic growth, as we showed in d'Albis et al. (2019).

To the best of our knowledge, there are few studies to date that consider the effects of the components of population growth on labor income share. Glover and Short (2018) estimate the effect of the age-distribution of earnings on the labor income share. However, they propose a link between demographics and the strength of competition. Indeed, their micro foundation for the effect of the interaction between age and labor share rests on monopsony power in bilaterally matched labor markets. Acemoglu and Restrepo (2018b) suggest that population aging may give incentives to automation and hence contribute 
to higher productivity and growth. Conversely, it may also decrease employment and the labor income share. This channel is reinforced with a general equilibrium model by Basso and Jimeno (2020), where the authors analyze the trade-offs between the goods while studying the consequences of population aging. They find that population aging increases automation and is therefore detrimental to economic growth and the labor income share. Our results complement them as we point out that it is only the aging produced by a lower migration that would reduce the labor income share.

We also rely on the large literature analyzing the explanatory factors of the observed evolution of the labor income share (see Alvarez-Cuadrado et al., 2018 and Cette et al., 2019 for a survey of the literature). Our results suggest that demography influences the labor income share but has probably a quantitatively lower influence than the factors discussed in this literature, namely the product and labor market regulations (Blanchard and Giavazzi, 2003), globalization (Böckerman and Maliranta, 2012; Elsby et al., 2013; Reshef and Santoni, 2019), the capital biased technology growth (Karabarbounis and Neiman, 2014), technology (Autor et al., 2020; Aghion et al., 2019) and most notably automation (Acemoglu and Restrepo, 2018a,b; Bergholt et al., 2019; Basso and Jimeno, 2020) and variations in competition (Gutiérrez and Philippon, 2019; Philippon, 2019).

\subsection{Discussion}

This section proposes a simple rationalization of our results using a standard neoclassical production function. Let $K_{t}$ and $L_{t}$ be the stock of capital and the labor force at time $t$ and $k_{t}:=K_{t} / L_{t}$ be the capital to labor ratio. A shock on the rate of natural increase is unlikely to modify the capital to labor ratio on the short run as newborns enter the labor force with a delay. After a few years, this shock is likely to reduce the ratio featuring then a traditional capital dilution effect. A shock on the net migration rate is susceptible to impact more quickly the capital to labor ratio, as migrant are mostly of adult age and can then be employed. As long as the capital is fixed, the ratio is thus expected to decrease but as soon as period $t+1$, the effect can be reversed. In the Proposition 2 in d'Albis et al., 2019, we showed that it can be the case in a simple general equilibrium model 
where the fiscal impact of migration is taken into account. This demographic dividend of migration is, in particular, strong for aging populations such as those of OECD countries. In short, the rate of natural increase and the net migration rate are susceptible to have opposite effects on the capital to labor ratio, negative for the former and positive for the latter.

Let us now consider a neoclassical production function denoted $F\left(K_{t}, L_{t}\right)$, which is supposed to be homogenous of degree 1 and increasing and concave with respect to its arguments. The labor income share, denoted $\alpha_{t}$, is thus simply defined as:

$$
\alpha_{t}=\frac{F_{2}^{\prime}\left(K_{t}, L_{t}\right) L_{t}}{F\left(K_{t}, L_{t}\right)}
$$

and can be rewritten as:

$$
\alpha_{t}=\frac{F_{2}^{\prime}\left(k_{t}, 1\right)}{F\left(k_{t}, 1\right)}
$$

The labor income share is thus equal to the ratio of wages to productivity, which both decrease with the capital to labor ratio. A simple derivation of 5 gives the relation between the labor income share and the capital to labor ratio:

$$
\frac{d \alpha_{t}}{d k_{t}} \geq 0 \Leftrightarrow \varepsilon_{K, L} \leq 1
$$

where $\varepsilon_{K, L}$ is the elasticity of substitution between capital and labor. Our main finding can thus be rationalized if $\varepsilon_{K, L}<1$ : the labor income share decreases with the natural rate of increase and increases with the net migration rate.

The empirical literature that seeks to estimate the elasticity of substitution between capital and labor is extensive and appears to converge on a value less than 1 . In particular, León-Ledesma et al. (2015) find an elasticity close to 0.7 for the United States, a complementarity that is confirmed by Bergholt et al. (2019), who estimate a structural VAR. A recent meta-analysis by Knoblach et al. (2019) of 77 studies published between 1961 and 2017 showed that mean elasticity was 0.54 , and 0.77 when the precision of the estimates was taken into account. A notable exception in this literature is Karabarbou- 
nis and Neiman (2014), where the authors estimate the relationship between the labor income share and the relative price of capital goods. Analyzing a large cross-section of countries, they find, ceteris paribus, a positive correlation between the two variables, from which one might conclude that the elasticity between capital and labor is greater than $1 .{ }^{5}$ However, including the heterogeneity of the labor force and technical progress is sufficient to obtain a positive correlation between the labor income share and the relative price of capital goods where elasticity is less than 1 (Cette et al., 2019). Moreover, Glover and Short (2019) estimate an elasticity near or below 1 using the same data set and theoretical framework as Karabarbounis and Neiman (2014). They show that Karabarbounis and Neiman (2014)'s estimate might be biased upwards due to omitted variable bias because the latter use investment prices alone to proxy for the rental rate, whereas the growth model relates rental rates to investment prices and consumption growth. This empirical finding gives some perspective to the rationalization presented above.

\section{Robustness analysis}

\subsection{Anticipation issue}

A traditional problem in the identification of shocks in VAR frameworks is the so-called foresight or anticipation effect. The anticipation issue has been most notably mentioned for monetary shocks (Stock and Watson, 2001) and fiscal shocks (Blanchard and Perotti, 2002; Beetsma and Guiliodori, 2011; Leeper et al., 2013). Analogously, with migration, we may face two types of anticipation issues, leading to difficulty in appropriately identifying migration shocks in the recursive Cholesky identification scheme. First, one may argue that migration may be influenced by anticipation of future economic conditions in the host country. Indeed, the decision to migrate may be based on migrants' anticipation of destination country, and governments of host countries may also change their migration policy in response to expectations about future economic outcomes. Second,

\footnotetext{
${ }^{5}$ A similar reasoning may be found in Piketty and Zucman (2014), where the authors note that the return on capital has fallen less in the last 40 years than the capital-output ratio, which may also be due to an elasticity between capital and labor greater than 1 .
} 
agents in host countries may form expectations about the future flows of migrants and respond to them by modifying their economic choices. If those behaviors are significant, they challenge our recursive Cholesky identification scheme based on the argument that the decision to migrate abroad is made on observed information on past economic conditions and migration policy in the destination country. Similarly, we can also imagine a potential anticipation effect for natural increase, particularly for fertility decisions. Indeed, expectations about future economic conditions may affect fertility behaviors, as children represent financial and opportunity costs. Moreover, current economic decisions may react to anticipations of the evolution of natural increase.

Our aim here is to establish that these potential anticipation issues have no consequences on the identification of our demographic shocks. In line with the literature on macroeconomic shocks (see Ramey, 2016 for a review), we include in the VAR system a variable with a strong forward-looking component to capture changes in agents' expectations about future economic conditions. The variable we choose is a stock market index (see Appendix A.1 for more details) following Beaudry and Portier (2006). This follows the recommendation of Sims (2009) to add as many observable states and other forward-looking variables as feasible in order to reduce any potential bias in a model with non-invertibility, that is situations where innovations from a VAR do not reflect the shocks of the economic model well. We thus add to our baseline VAR the logarithm of a stock market index and order it first in the Cholesky scheme, as in the literature. The corresponding results are reported in Figure 4 . These results are roughly the same as those of the baseline model reported in Figure 3, confirming our initial conjecture that anticipation issues do not matter for demographic shocks. This reflects the predominance of unanticipated factors (such as geopolitical tensions and natural disasters) causing migration fluctuations or the difficulty in anticipating a change in migration policy (Massey and Pren, 2012).

[Figure 4] 


\subsection{Identification based on sign restrictions}

Our results are obtained using a recursive identification scheme based on the assumption that demographics are the most exogenous variables. Even if this assumption is highly plausible, we check the robustness of our results by using an alternative identification that is not recursive and that is based on sign restrictions. This approach has been employed by d'Albis et al. (2016, 2019) and Furlanetto and Robstad (2019) to explore the macroeconomic consequences of international migration.

As in d'Albis et al. (2019), we use sign restrictions with the penalty function criterion developed by Uhlig (2005). The purpose of this approach, instead of identifying all elements in matrix $A$, is to find a vector column $a$ of $A$ (the reaction of variables to a given structural shock) minimizing the following function:

$$
\Psi(a)=\sum_{k} \sum_{h=0}^{H} \psi\left(\tau_{k} \frac{\lambda_{k, h}(a)}{\sigma_{k}}\right)
$$

where $\psi$ is the function $\psi(x)=x$ if $x \leq 0$ and $\psi(x)=100 \times x$ if $x>0, \lambda_{k, h}(b)$ is the impulse response of the variable $k$ to the impulse vector $a$ at horizon $h, \sigma_{k}$ is the standard error of variable $k, \tau_{k}=-1$ if the impulse response of the variable $k$ is restricted to be positive and $\tau_{k}=1$ otherwise. To identify shocks, we follow the sequential procedure of Mountford and Uhlig (2009). Rather than identifying the two demographic shocks only, we start by identifying a business cycle shock that is orthogonal to both demographic shocks. This permits us to filter out the endogenous responses of migration and natural increase to the business cycle, and to attribute as many movements of variables in the system as possible to this shock (Mountford and Uhlig, 2009). The procedure is as follow. First, the business cycle shock is identified using the penalty function criterion so that this shock increases labor and capital incomes for the first two years. Second, the migration shock is then identified via the criterion function so that it raises the net migration rate over the same horizon of two years, with the additional condition to be orthogonal to the business cycle shock. Third, the natural increase shock is identified by the penalty function criterion so that it raises the rate of natural increase over the same horizon of two 
years, and subject to the restriction to be orthogonal to the business cycle and migration shocks. Notice that the ordering of identification between migration and natural increase shocks has no effect on our findings.

The estimates of the impulse responses based on sign restrictions are reported in Figure 5. These results are roughly similar to those of the baseline model. Therefore, identifying shock through penal criterion clearly reinforces our previous finding based on a recursive identification.

[Figure 5]

\subsection{Alternative specifications}

To carry out additional robustness checks of our results, we estimate additional specifications by including unemployment in the model and studying the dynamic responses induced by alternative demographic variables.

We first obtained that the inclusion of the unemployment rate in the model does not alter our results (Figure 6). The effects of demographic shocks are roughly unchanged compared to the results of the baseline model. Interestingly, we found that a migration shock significantly reduces the unemployment rate, while the natural increase shock has no significant impact on the unemployment rate. This confirms the previous findings of Gross (2002), Damette and Fromentin (2013), d'Albis et al. (2018) and Esposito et al. $(2020)$.

[Figure 6]

Then, we grouped our two demographic variables in a single variable, namely the population growth rate. Our estimates (Figure 7) suggest that a population growth shock has a favorable effect on the economy. We observe that labor income per capita increases significantly during the nine years after, while total income per capita increases significantly during the three years, following a population growth shock. As a result, there is no immediate impact on the labor income share during the first two years, which rises significantly from three years to eleven years after the growth population shock. It is interesting to note that the impulse responses to population growth shock are similar 
to the impulse responses to migration shock reported in Figure 3, which is confirmed by the comparison of the forecast error variance decomposition results reported in Tables 1 and 2. This reflects the fact that, in the OECD countries over the 1985-2018 period, fluctuations in population growth are mainly driven by international migration.

\section{[Figure 7]}

Finally, we decomposed the natural increase between birth and death. The results (Figure 8) show that following a shock on birth rate, both labor and total incomes per capita increase significantly only on impact. These responses of labor and total incomes result in an insignificant impact of a birth shock on the labor income share. In response to a shock on death rate, labor income rises significantly from two to ten years after the shock, while total income increases significantly from two years to seven years after the shock. As a result, a shock on death rate leads to a significant decrease in the labor income share from twenty-four to thirty years after the shock. The impact of birth and death shocks on income are consistent with Nicolini (2007). ${ }^{6}$ We also note that the responses to migration shock in this extended model are similar to those of our baseline model.

[Figure 8]

\subsection{Income inequality}

The labor income share measures a specific inequality arising between capital and labor incomes. We now extend our analysis to other inequality measures. In the literature, various dispersions are considered, on wages (Katz and Murphy, 1992) or incomes (Atkinson, 1997), which are closely related, as they are likely to have similar determinants. In addition to earnings, income includes self-employed earnings, capital incomes, and potentially transfers net of income taxes and social security contributions. The main difficulty for our purpose is to have comparable international data over a sufficiently long period. We thus rely on the income distribution indicators provided by the World Inequality Database (Alvaredo et al., 2018).

\footnotetext{
${ }^{6}$ As noted by Nicolini (2007), it is difficult to gauge the influence of fertility and a model with many more lags is needed to capture the effect of the larger cohort entering the labor force. However, we can't do that here, given the limited time-dimension of our sample $(T=34)$.
} 
We first note that variation in the labor income share negatively correlates with income inequality. To establish this, we examine the statistical link between the labor income share and the share of pre-tax national income held by a given percentile group: the top $1 \%$, the top $10 \%$, the middle $40 \%$ and the bottom $50 \%$ shares of income, denoted $\tilde{y} 1 p$, $\tilde{y} 10 p, \tilde{y} 40 p$, and $\tilde{y} 50 p$, respectively (see Appendix A.1 for more details). Figure 9 presents the empirical relationship between the labor income share and each income distribution measure for 14 OECD countries of our sample over the period 1985-2014.

\section{[Figure 9]}

Figure 9 shows a negative relationship between labor income share and $\tilde{y} 1 p$ and $\tilde{y} 10 p$, and a positive relationship between labor income share and $\tilde{y} 40 p$ and $\tilde{y} 50 p$. These relationships are statistically significant. A related question is whether labor income series are useful in forecasting personal income distribution series, for which data is scarce. To specify the causal relationship between these two series, we rely on the panel Granger causality test developed by Dumitrescu and Hurlin (2012). This is an extension of Granger causality for panel data while allowing for heterogeneity of cross-sectional units. Formally, the causality test from variable $x$ to variable $y$ is implemented based on the following heterogeneous autoregressive model:

$$
y_{i t}=\sum_{s=1}^{q} \phi_{i s} y_{i t-s}+\sum_{s=1}^{q} \psi_{i s} x_{i t-s}+\alpha_{i}+\eta_{t}+\omega_{i t} \quad i=1, \ldots, N \text { and } t=1, \ldots, T
$$

where $\alpha_{i}$ are country-fixed effects, $\eta_{t}$ are common year-specific effects that aim to account for cross-country contemporaneous interdependence, and $\omega_{i t}$ are idiosyncratic error terms. The null hypothesis of homogeneous non-causality from $x$ to $y\left(H_{0}: \psi_{i 1}=\psi_{i 2}=\ldots=\right.$ $\left.\psi_{i q} i=1, \ldots, N\right)$ is tested using the cross-sectional average of individual Wald statistics for the Granger non-causality hypothesis for each country $i$. The test statistics are computed based on the cross-sectional Wald statistics and under the null hypothesis of homogenous non-causality, it follows the standard normal distribution (with mean equal to 0 and standard deviation equal to 1$)$.

Table 3 shows the results of panel Granger causality between labor income share and the indicators of income distribution. As above, the lag length is set to two in the 
autoregressive model of causality.

\section{[Table 3]}

For each measure of income distribution, at the conventional level of significance, the null hypothesis of non-causality from labor income share to income distribution is strongly rejected, while we cannot reject the null hypothesis of non-causality from income distribution to labor income share. While testing the causality from labor income share to income distribution, we note that the signs of estimated coefficients $\psi_{i 1}$ and $\psi_{i 2}$ are, on average, in line with the negative or positive relationship described in Figure 9. To conclude, this test suggests that the relationship established in Figure 9 reflects the fact that past information in labor income share is useful for predicting future development in income distribution, but that the converse is not true. The intuition hinges on the fact that capital ownership is concentrated among the richest, meaning that a decline in the labor share benefits the top income brackets (see, for instance, Piketty, 2014 and IMF, 2017). These results are consistent with Checchi and García-Peñalosa (2010), where the authors examine the determinants of personal income inequality using data for a panel of OECD countries over the period 1960-2000. Among the determinants, they consider the labor income share. Their results show that an increase in the labor income share reduces the Gini coefficient computed on personal incomes.

We next turn to the effects of demographic shocks on income distribution. We replace, in our baseline VAR specifications, labor and capital incomes by the national income and an inequality measure. We consider four additional specifications to evaluate the responses of income distribution indicators to natural increase and migration shocks (see Appendix A.2 for more details). The results are presented in Figure 10.

\section{[Figure 10]}

We notice that in reaction to a shock on natural increase, none of the income distribution indicators considered, respond significantly. Concerning the migration shock, $\tilde{y} 10 p$ decreases significantly around five to eight years after the shock, $\tilde{y} 50 p$ increases significantly from the fourth year and until the eighth year after the shock, while $\tilde{y} 1 p$ and $\tilde{y} 40 p$ do not respond significantly. It is interesting to highlight that it is those of the lower half 
of the income distribution that benefited from the international migration flows. These results generally suggest that international migration does not produce more inequalities.

An abundant literature in the 1980's studied the effect of demography on income distribution and suggested that most population variables increased inequality (see Pestieau, 1989, for a review that discusses conceptual and methodological issues). However, there was a controversy on inequality measures ${ }^{7}$ and whether demographic factors were exogenous or influenced by economic factors, which challenged the first conclusions (Lam, 1987). Our main results deal with these issues by considering labor income share rather than income class indicators and by estimating a VAR that take into account the endogeneity of demographic variables. More recently, the literature has focused on the distributional effects of immigration, and most notably, whether the immigration-induced shift in labor supply has increased the wage differentials between skill groups. For the United States, Borjas et al. (1997) concluded that immigration accounted for at most a small share of the increase in overall wage inequality while Card (2009) showed that immigration had a very small impact on wage inequality among natives. For France, Edo and Toubal (2015) find that immigration has decreased wage inequality between highly educated and less educated native workers over the period 1990-2010. Other studies focused on the distribution of earnings as an inequality measure. Dustmann et al. (2013) analyzed the effect of immigration on the distribution of native wages in the UK and found that immigration depresses native wages below the 20th percentile of the wage distribution but leads to slight wage increases in the upper part of the wage distribution. Lerman (1999) shows that the estimated rise in wage inequality in the United States disappears when the evolution of the wages of recent immigrants is taken into account. Beyond the impact of immigration on the relative wages or on the wage distribution, Ortega and Peri (2014) examine whether immigration affects the Gini coefficient and the 90-10 ratio of income percentiles. Based on a data set of 117 developed and developing countries around 2000, they find no evidence of an effect of immigration on the distribution of income. Relying on a panel of OECD countries over the period 1985-2018, our

\footnotetext{
${ }^{7}$ For instance, Lam (1986) found that most standard inequality measures yield conflicting signals in the presence of differential fertility.
} 
estimation results are consistent. The net flow of permanent migrants did not seem to increase income inequality in OECD countries.

\section{Conclusion}

In this article we have analyzed the effects of demographic variables on the labor income share by distinguishing between natural increase and migration. We have shown empirically that these two variables have opposite effects on the economy: natural increase reduces per capita total income and the labor income share, whereas migration increases per capita total income and labor income share. These empirical findings are consistent with the neoclassical growth framework as long as the elasticity of substitution between capital and labor is less than 1.

This research could be improved in various ways. In particular, it would be instructive to go beyond the inequality between capital and labor and push for the examination of the effects of demographic variables on the disparity of income distribution among the population. We provided a first analysis in the robustness section but the challenge for macro-economic analysis is the availability of data. In this article, we have used data provided by the World Income Database, but the temporal dimension of the database is somewhat limited. 


\section{References}

Acemoglu, D., Restrepo, P., 2018a. The race between machine and man: Implications of technology for growth, factor shares and employment. American Economic Review, 108(6): 1488-1542.

Acemoglu, D., Restrepo, P., 2018b. Demographics and automation. NBER Working Papers 24421.

Aghion, P., Bergeaud, A., Boppart, T., Klenow P., H., 2019. A theory of falling growth and rising rents. Mimeo. April.

Aksoy, Y., Basso, H. S., Smith, R. P. Grasl, T., 2019. Demographic structure and macroeconomic trends. American Economic Journal: Macroeconomics, 11(1): 193-222.

d'Albis, H., Boubtane, E., Coulibaly, D., 2016. Immigration policy and macroeconomic performances in France. Annals of Economics and Statistics 121-122, 279-308.

d'Albis, H., Boubtane, E., Coulibaly, D., 2018. Macroeconomic evidence suggests that asylum seekers are not a burden for Western European countries. Science Advance 4 (6): eaaq0883.

d'Albis, H., Boubtane, E., Coulibaly, D., 2019. Immigration and public finances in OECD countries. Journal of Economic Dynamics and Control, 99: 116-151.

Alvaredo, F., Chancel, L., Piketty, T., Saez, E., Zucman, G., 2018. World Inequality (Database).

Alvarez-Cuadrado, F., Van Long, N., Poschke, M., 2018. Capital-labor substitution, structural change and the labor income share. Journal of Economic Dynamics and Control, 87: 206-231.

Atkinson, A. B., 1997. Bringing the income distribution in from the cold. Economic Journal, 107: 297-321.

Autor, D., Dorn, D., Katz, L., F., Patterson, C., Van Reenen, J., 2020. The fall of the labor share and the rise of superstar firms, Quarterly Journal of Economics , $135(2): 645-709$. 
Basso, H.S., Jimeno, J. F., 2020. From secular stagnation to robocalypse? Implications of demographic and technological changes. Journal of Monetary Economics Forthcoming.

Beetsma, R., Giuliodori, M., 2011. The effects of government purchases shocks: Review and estimates for the EU. The Economic Journal 121, F4-F32.

Bergholt, D., Furlanetto, F., Maffai Faccioli, N., 2019. The labor share decline: New empirical evidence. Norges Bank: Working Papers.

Blanchard, O.J., Perotti, R., 2002. An empirical characterization of the dynamic effects of changes in government spending and taxes on output. Quarterly Journal of Economics, 117: $1329-1368$.

Blanchard, O.J., Giavazzi, F., 2003. Macroeconomic effects of regulation and deregulation in goods and labor markets. The Quarterly Journal of Economics, 118(3):879-907.

Bloom, D. E., Canning, D., Sevilla, J., 2001. Economic growth and the demographic transition. NBER Working Paper 8685.

Bloom, D. E., Williamson, J., 1998. Demographic transitions and economic miracles in emerging Asia. The World Bank Economic Review, 12(3): 419-455.

Böckerman, P., Maliranta, M., 2012. Globalization, creative destruction, and labour share change: evidence on the determinants and mechanisms from longitudinal plant-level data. Oxford Economic Papers, 64(2):259-280.

Beaudry, P., Portier, F., 2006. Stock prices, news, and economic fluctuations. American Economic Review, 96(4): 1293-1307.

Boubtane, E., Dumont, J. C., Rault, C., 2016. Immigration and economic growth in the OECD countries 1986-2006. Oxford Economic Papers, 62: 340-360.

Borjas, G. J., Freeman, R. B., Katz, L. F., DiNardo, J., Abowd, J. M., 1997. How much do immigration and trade affect labor market outcomes? Brookings Papers on Economic Activity, 1997(1):1-90.

Card, D. 2009. Immigration and inequality. American Economic Review, 99 (2); 1-21.

Cette, G., Koehl, L., Philippon, T., 2019. Labor shares in some advanced economies. NBER Working Paper 26136. 
Checchi, D. and García-Peñalosa, C., 2010. Labour market institutions and the personal distribution of income in the OECD. Economica, 77: 413-450.

Clemens, M. A., 2011. Economics and emigration: Trillion-dollar bills on the sidewalk? Journal of Economic Perspectives, 25: 83-106.

Damette, O., Fromentin, V., 2013. Migration and labour markets in OECD countries: A panel cointegration approach. Applied Economics, 45: 2295-2304.

Dumitrescu E. I., Hurlin, C., 2012. Testing for Granger non-causality in heterogeneous panels. Economic Modelling 29, 1450-1460.

Dustmann, C., Frattini, T., Preston, I. P., 2013. The effect of immigration along the distribution of wages. The Review of Economic Studies, 80(1); 145-173.

Eckstein, Z., Schultz, T. P., Wolpin, K. I., 1985. Short run fluctuations in fertility and mortality in pre-industrial Sweden. European Economic Review, 26:295-317.

Edo, A., Toubal, F., 2015. Immigration policies and wages inequality. Review of International Economics, 23: 160-187.

Elsby, M., Hobijn, B., Sahin, A., 2013. The decline of the U.S labor share. Brookings Papers on Economic Activity, 44(2): 1-63.

Esposito, P., Collignon, S., Scicchitano, S., 2020. The effect of immigration on unemployment in Europe: Does the core-periphery dualism matter? Economic Modelling, $84(\mathrm{C}): 249-258$.

Eurostat, 2020. Demography and migration (database).

Fernihough, A., 2013. Malthusian dynamics in a diverging Europe: Northern Italy, 16501881. Demography 50: 311-332.

Furlanetto, F., Robstad, Ø, 2019. Immigration and the macroeconomy: Some new empirical evidence. Review of Economic Dynamics,34: 1-19.

Glover, A., Short, J., 2018. Demographic origins of the decline in labor's share. Mimeo, November.

Glover, A., Short, J., 2019. Can capital deepening explain the global decline in labor's share? Review of Economic Dynamics, 34: 35-53. 
Gross, D. 2002. Three million foreigners, three million unemployed? Immigration flows and the labour market in France. Applied Economics, 34: 1969-1983.

Gutiérrez, G., Philippon, T., 2019. How EU markets became more competitive than US markets: A study of institutional drift. NBER Working Paper No. 24700.

Hahn, J., Kuersteiner, G., 2002. Asymptotically unbiased inference for a dynamic panel model with fixed effects when both $\mathrm{n}$ and T are large. Econometrica, 70: 1639-1657.

IMF, 2017. Understanding the downward trend in labor income shares. In World Economic Outlook: Gaining Monentum. International Monetary Fund, Publication Services. Washington.

Juessen, F., Linnemann, L., 2012. Markups and fiscal transmission in a panel of OECD countries. Journal of Macroeconomics, 34: 674-686.

Karabarbounis, L., Neiman, B., 2014. The global decline of the labor share. The Quarterly Journal of Economics, 129(1): 61-103.

Katz, L. F. and Murphy, K. M., 1992. Changes in relative wages, 1963-1987: supply and demand factors. Quarterly Journal of Economics, 107: 35-78.

Kim, B., 2016. Explaining movements of the labor share in the Korean economy: factor substitution, markups and bargaining power. The Journal of Economic Inequality, $14: 327-352$.

Knoblach, M., Roessler, M., Zwerschke, P., 2019. The elasticity of substitution between capital and labour in the US economy: A meta-regression analysis. Oxford Bulletin of Economics and Statistics, forthcoming.

Lam D., 1986. The dynamics of population growth, differential fertility, and inequality. American Economic Review, 76:1103-1116.

Lam D., 1987. Distribution issues in the relationship between population growth and economic development. In: Johnson DG, Lee RD (eds) Population Growth and Economic Development: Issues and Evidence. University of Wisconsin Press, Madison, WI.

Lawrence, R. Z., 2015. Recent declines in labor's share in US income: A preliminary neoclassical account. NBER Working Paper 21296. 
Leeper, E. M., Walker, T. B., Yang, S. C. S., 2013. Fiscal foresight and information flows. Econometrica 81, 1115-1145.

Lemaitre, G., Liebig, T, Thoreau, C., Fron, P., 2007. Standardised statistics on immigrant inflows results, sources and methods. OECD, Paris.

Lerman, R. I., 1999. U.S. Wage-inequality trends and recent immigration. American Economic Review, 89 (2): 23-28.

León-Ledesma, M. A., McAdam, P., and Willman, A., 2015. Production technology estimates and balanced growth. Oxford Bulletin of Economics and Statistics, 77: 40-65.

Massey, D. S., Pren, K. A., 2012. Unintended consequences of US immigration policy: Explaining the post-1965 surge from Latin America. Population and Development Review $38,1-29$.

Mountford, A., Uhlig, H., 2009. What are the effects of fiscal policy shocks? Journal of applied econometrics 24, 960-992.

Nickell, S. J., 1981. Biases in dynamic models with fixed effects. Econometrica, 49: 14171426.

Nicolini, E., 2007. Was Malthus right? A VAR analysis of economic and demographic interactions in pre-industrial England. European Review of Economic History, 11: 99121.

OECD, 2017. Labour Force Statistics: Population and Vital Statistics (Edition 2017) OECD Employment and Labour Market Statistics (database).

OECD, 2018. OECD Economic Outlook No. 103 (Edition 2018/1) OECD Economic Outlook: Statistics and Projections (database).

OECD, 2020a. Aggregate National Accounts, SNA 2008: Gross Domestic Product, OECD National Accounts Statistics (database).

OECD, 2020b. Finance, OECD Main Economic Indicators (database).

Ortega, J., Peri, G., 2014. Openness and income: The roles of trade and migration. Journal of International Economics, 92: 231-251.

Pestieau, P., 1989. The demographics of inequality. Journal of Population Economics, 
2(1): $3-24$.

Philippon, T., 2019. The Great Reversal, Harvard University Press.

Piketty, T., 2014. Capital in the Twenty-First Century. Cambridge, Massachusetts: Harvard University Press.

Piketty, T., Zucman, G., 2014. Capital is back: Wealth-income ratios in rich countries 1700-2010. The Quarterly Journal of Economics,129(3), 1255-1310.

Ramey, V.A., 2016. Macroeconomic shocks and their propagation. In: John B.T., Uhlig, H. (eds) Handbook of Macroeconomics, Volume 2, Elsevier.

Reshef, A., Santoni, G., 2019. Are your labor shares set in Beijing? The view through the lens of global value chains. CEPII working paper No. 2019-16.

Sims, C. A., 2009. Non-invertibilities and strucural VARs. Mimeo, University of Notre Dame.

Smith, C., Thoenissen, C., 2019. Skilled migration and business cycle dynamics. Journal of Economic Dynamics and Control 109, 103781.

Stock, J. H., Watson, M. W., 2001. Vector autoregressions. Journal of Economic Perspectives $15,101-115$.

Uhlig, H., 2005. What are the effects of monetary policy on output? Results from an agnostic identification procedure. Journal of Monetary Economics 52, 381-419.

UN, EC, IMF, OECD, WB, 2009. System of National Accounts 2008. New York: United Nations. 


\section{$6 \quad$ Figures and tables}

Figure 1: The source of population growth

(a) Population growth by component, OECD average

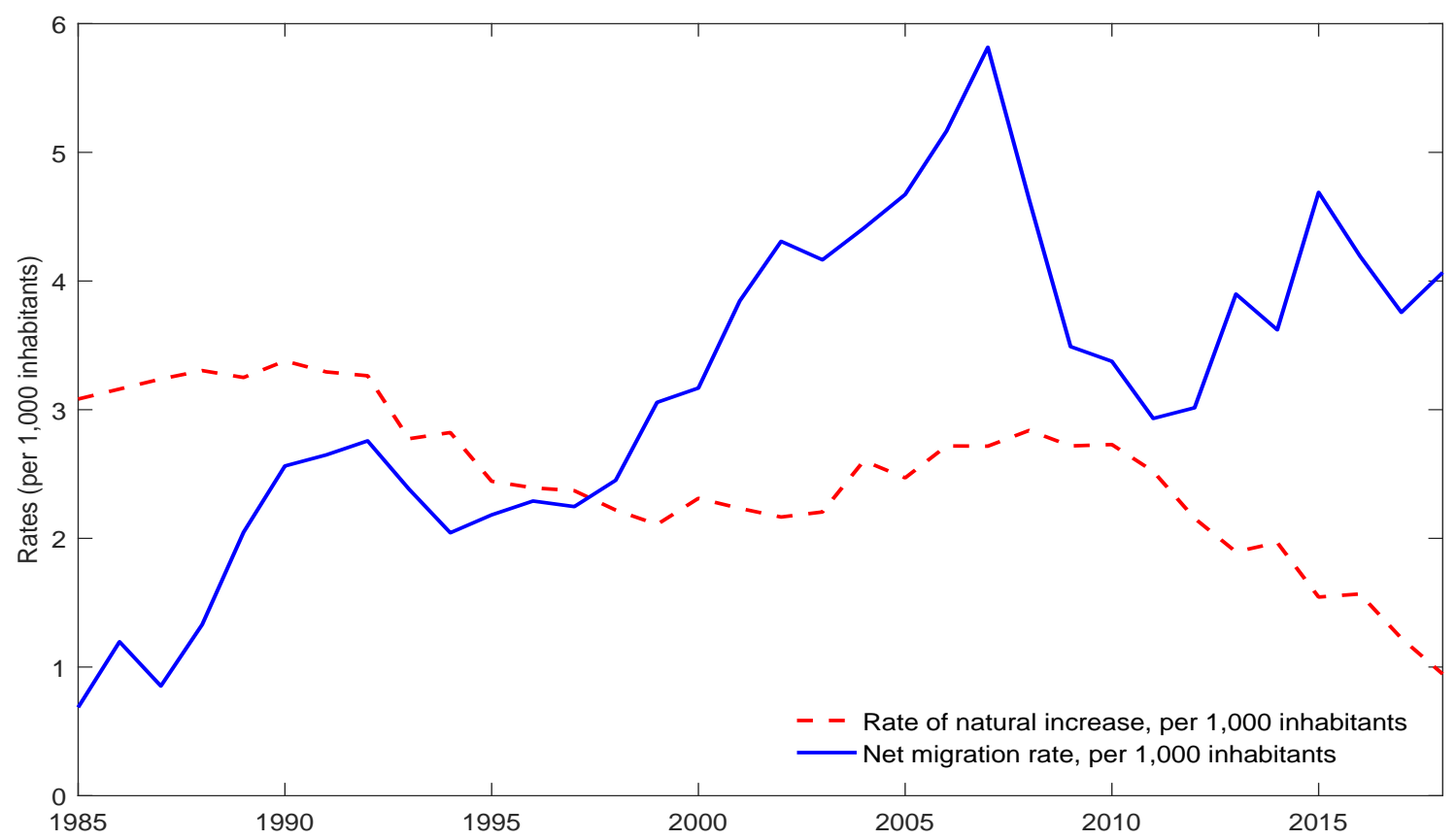

(b) Percentage of OECD countries with net migration rate exceeding the rate of natural increase

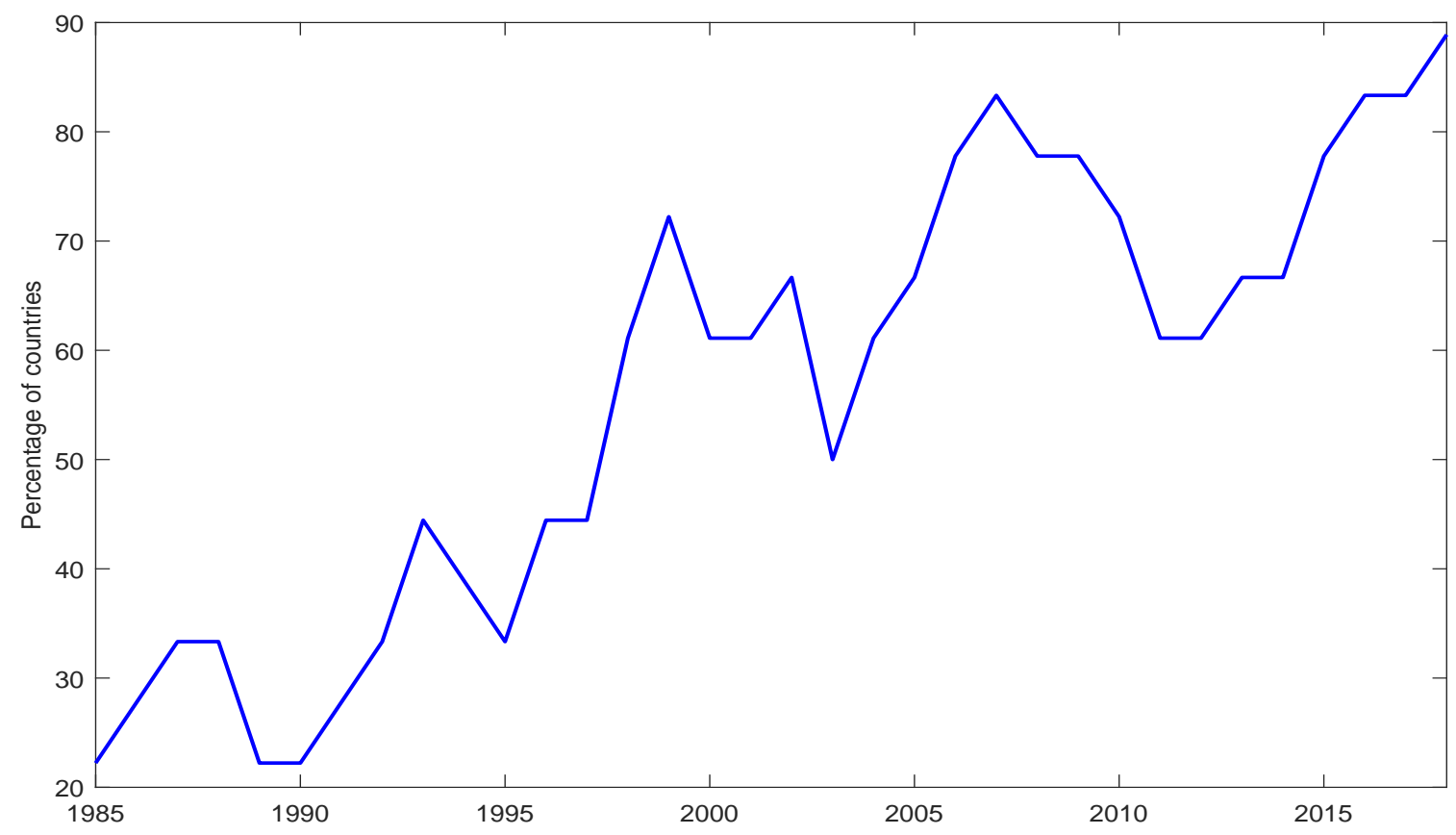

Source: Eurostat (2020) and OECD (2017) databases, Authors' computations.

Note: 18 OECD countries: Australia, Austria, Belgium, Canada, Denmark, Finland, France, Germany, Ireland, Italy, Japan, the Netherlands, Norway, Portugal, Spain, Sweden, the United Kingdom and the United States. 
Figure 2: Natural increase and net migration (per 1,000 inhabitants)
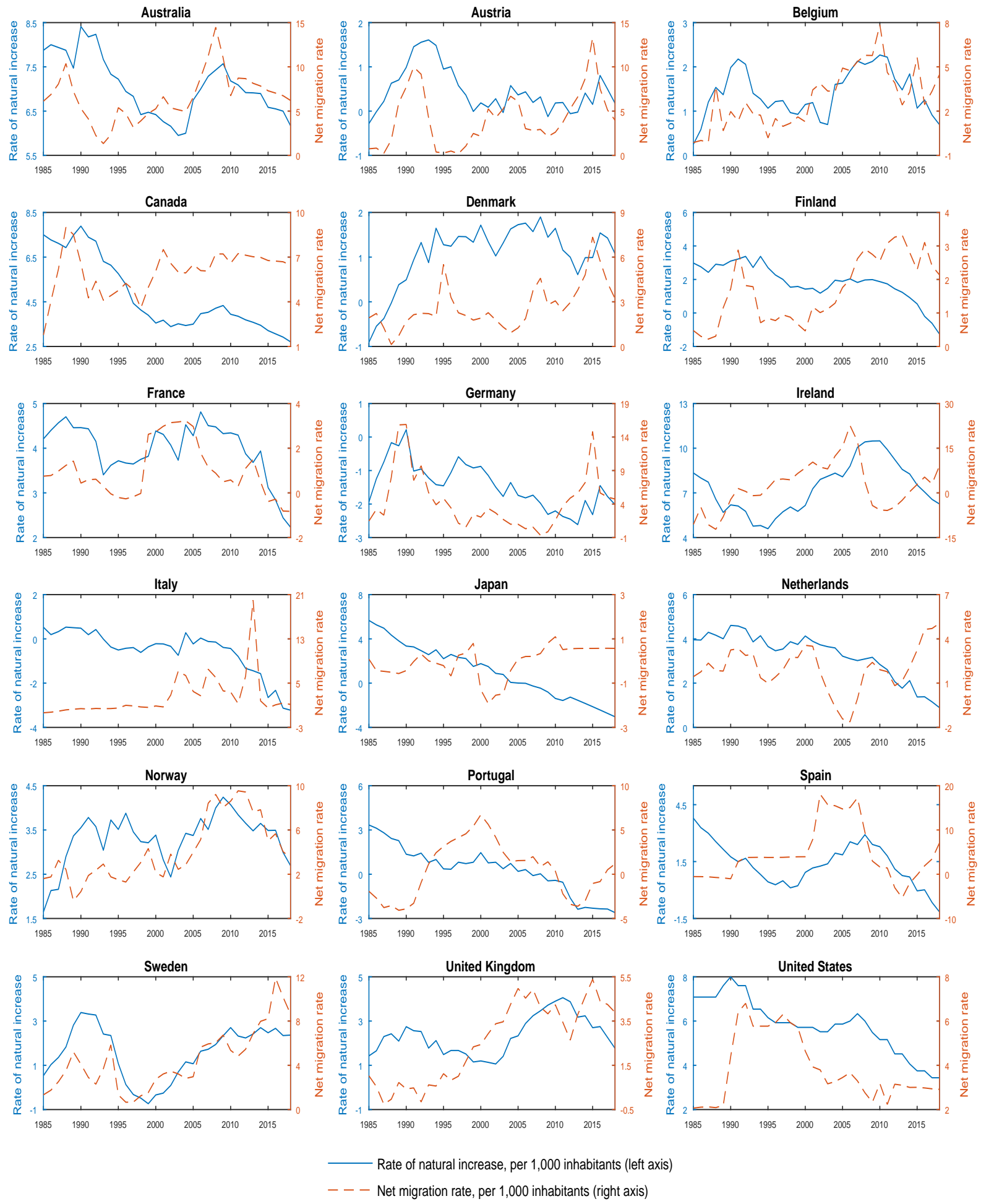

Source: Eurostat (2020) and OECD (2017) databases, Authors' computations. 
Figure 3: Responses to natural increase and migration shocks
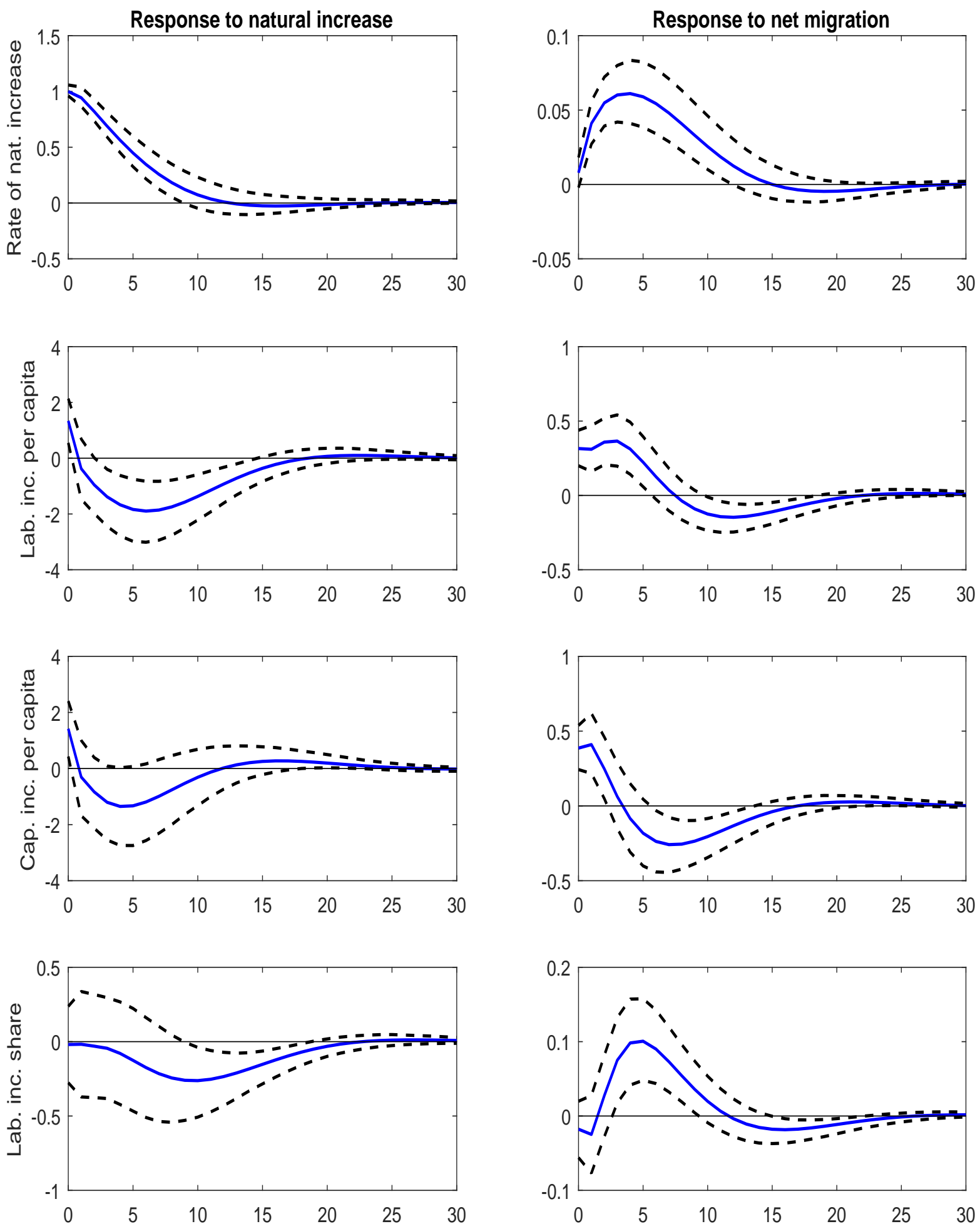

Notes: The solid line gives the estimated impulse response. Dashed lines give the $90 \%$ confidence intervals generated by Monte Carlo simulations with 5000 repetitions. The size of shocks is set to 1 per 1,000 inhabitants. The response of natural increase is in per 1,000 points change. The responses of per capita economic variables are in percentage change. For the labor income share, the response is in percentage points change. 
Table 1: Percentage of the fluctuations attributable to natural increase and migration shocks

\begin{tabular}{lcccccccc}
\hline & Year 0 & Year 1 & Year 2 & Year 5 & Year 10 & Year 15 & Year 20 & Year 30 \\
\hline Percentage of the fluctuations attributable to & natural & increase & shock & & & \\
Rate of natural increase & 99.72 & 95.33 & 90.17 & 75.93 & 63.87 & 61.56 & 61.35 & 61.31 \\
Net migration rate & 0.00 & 0.07 & 0.31 & 2.37 & 4.92 & 5.18 & 5.16 & 5.17 \\
Labor income per capita & 1.28 & 0.87 & 1.04 & 3.14 & 6.60 & 7.20 & 7.17 & 7.17 \\
Capital income per capita & 0.90 & 0.58 & 0.62 & 1.38 & 1.85 & 1.85 & 1.90 & 1.90 \\
Total income per capita & 1.55 & 1.08 & 1.22 & 3.15 & 5.40 & 5.54 & 5.53 & 5.54 \\
Labor income share & 0.00 & 0.00 & 0.01 & 0.07 & 0.76 & 1.31 & 1.39 & 1.39 \\
& & & & & & & & \\
Percentage of the fluctuations attributable to & migration shock & & & & \\
Rate of natural increase & 0.28 & 3.97 & 7.54 & 14.99 & 18.39 & 18.12 & 18.10 & 18.12 \\
Net migration & 100.00 & 99.71 & 98.26 & 90.90 & 85.59 & 84.73 & 84.46 & 84.41 \\
Labor income per capita & 3.19 & 3.97 & 5.34 & 7.83 & 7.58 & 8.41 & 8.55 & 8.55 \\
Capital income per capita & 3.01 & 3.96 & 3.77 & 3.36 & 5.28 & 5.67 & 5.67 & 5.70 \\
Total income per capita & 4.45 & 6.00 & 6.67 & 6.23 & 6.78 & 7.63 & 7.67 & 7.68 \\
Labor income share & 0.10 & 0.17 & 0.25 & 3.29 & 5.21 & 5.24 & 5.36 & 5.37 \\
\hline
\end{tabular}

Notes: Year 0 stands for the year of the shock. The percentage of fluctuations
the forecast error variance of the corresponding variable explained this shock. 
Figure 4: Responses to natural increase and migration shocks, anticipation issue
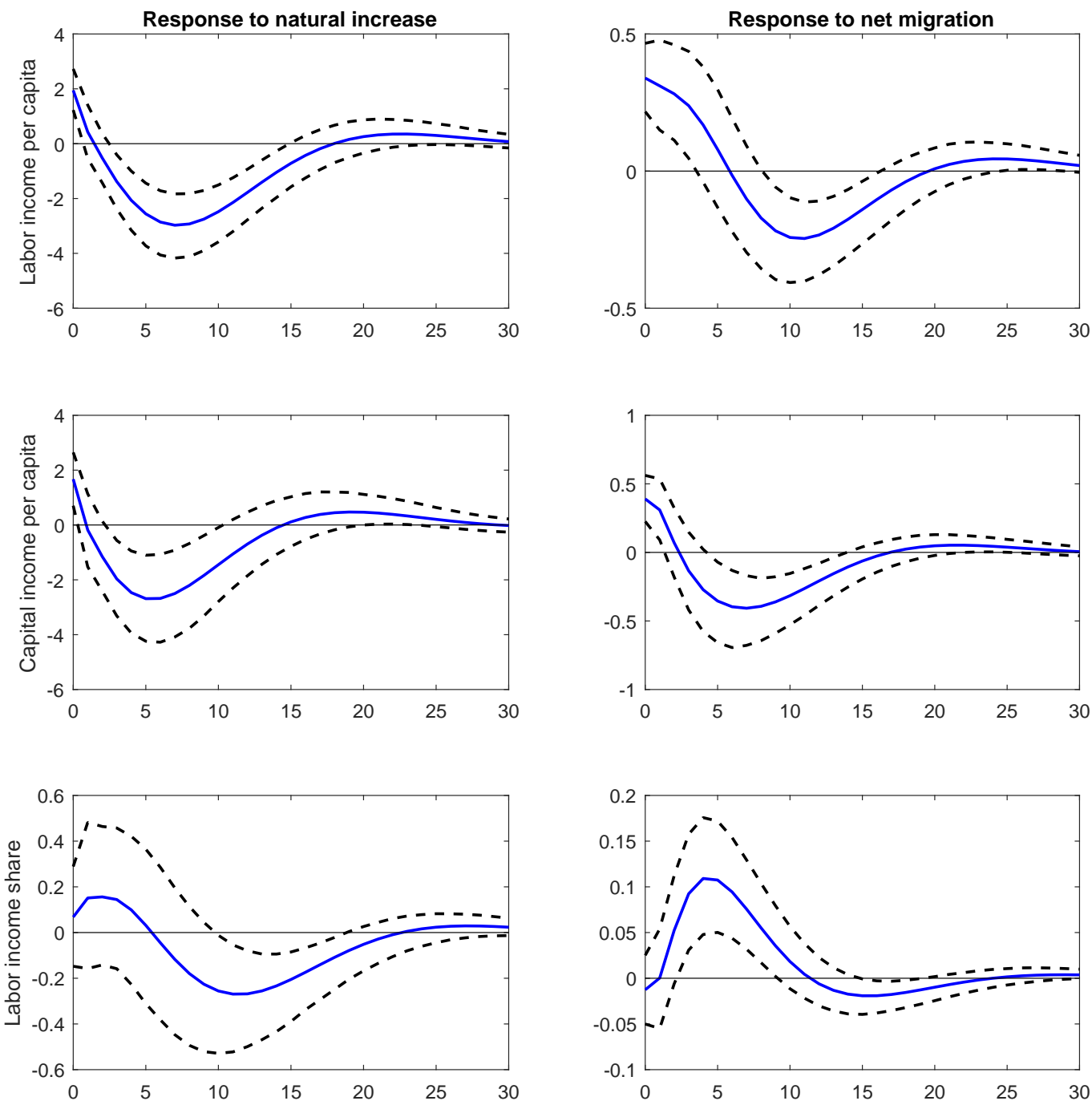

Notes: The solid line gives the estimated impulse response. Dashed lines give the $90 \%$ confidence intervals generated by Monte Carlo simulations with 5000 repetitions. The size of shocks is set to 1 per 1,000 inhabitants. The responses of demographic variables are in per 1,000 points change. The responses of per capita economic variables are in percentage change. For the labor income share, the response is in percentage points change. 
Figure 5: Responses to natural increase and migration shocks, using sign restrictions.
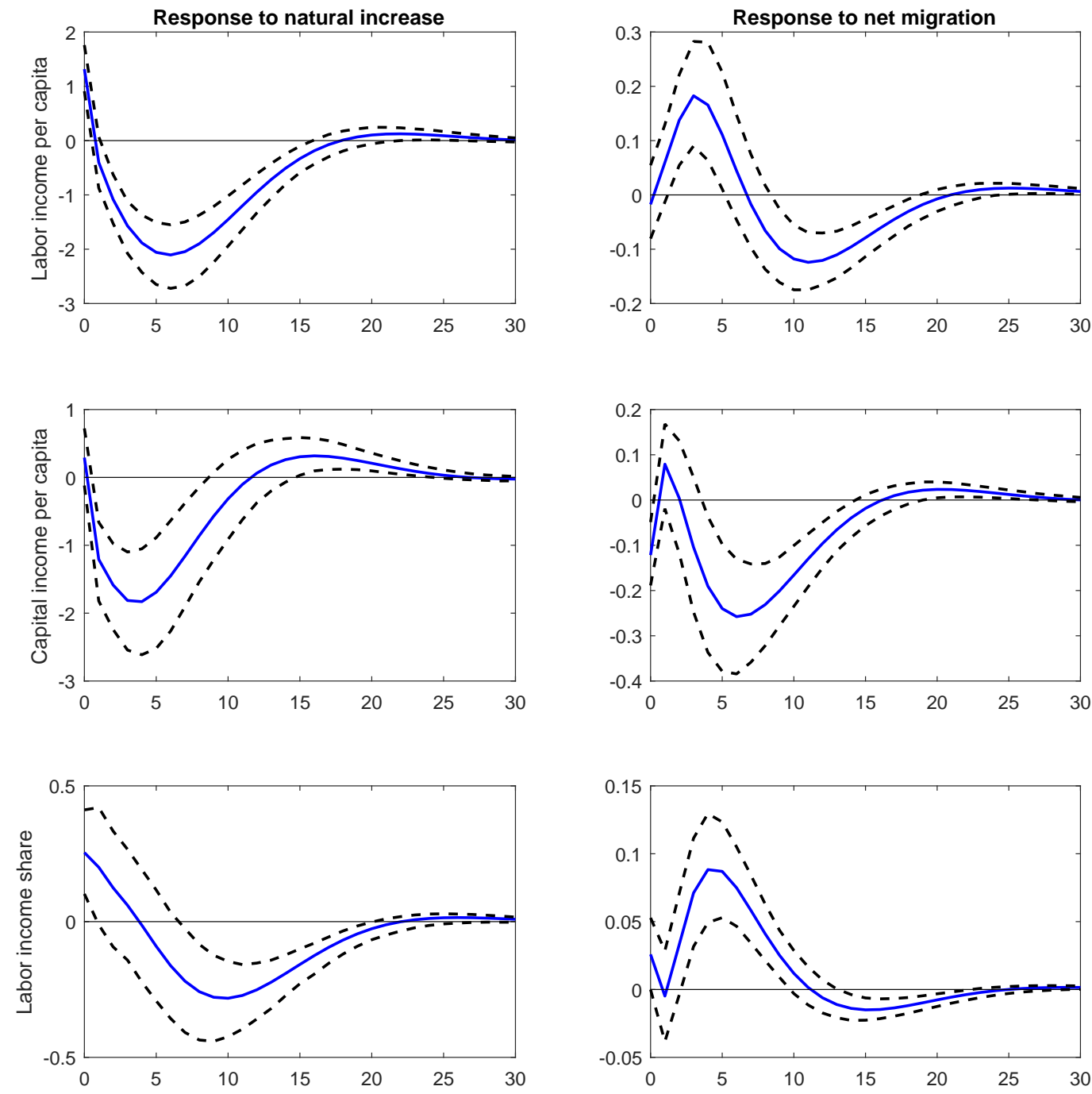

Notes: The solid line gives the estimated impulse response. Dashed lines give the $68 \%$ confidence intervals computed by the Bayesian approach by tacking 5000 draws from the posterior of the VAR coefficients and the variance-covariance matrix of errors. The size of shocks is set to 1 per 1,000 inhabitants. The responses of demographic variables are in per 1,000 points change. The responses of per capita economic variables are in percentage change. For the labor income share, the response is in percentage points change. 
Figure 6: Responses to natural increase and migration shocks in model with unemployment
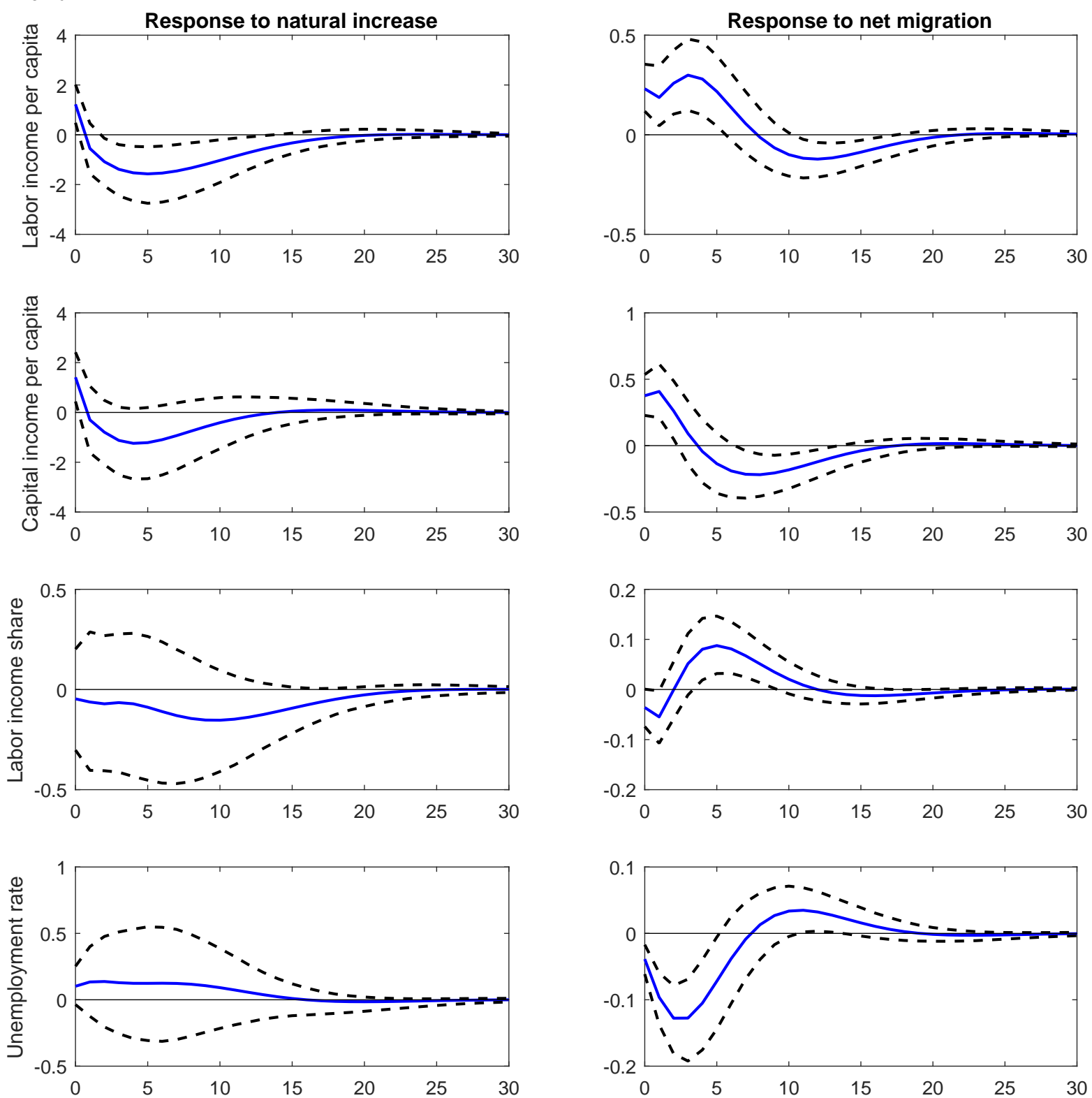

Notes: The solid line gives the estimated impulse response. Dashed lines give the $90 \%$ confidence intervals generated by Monte Carlo simulations with 5000 repetitions. The size of shocks is set to 1 per 1,000 inhabitants. The responses of demographic variables are in per 1,000 points change. The responses of per capita economic variables are in percentage change. For the labor income share, the response is in percentage points change. 
Figure 7: Responses to population growth shock
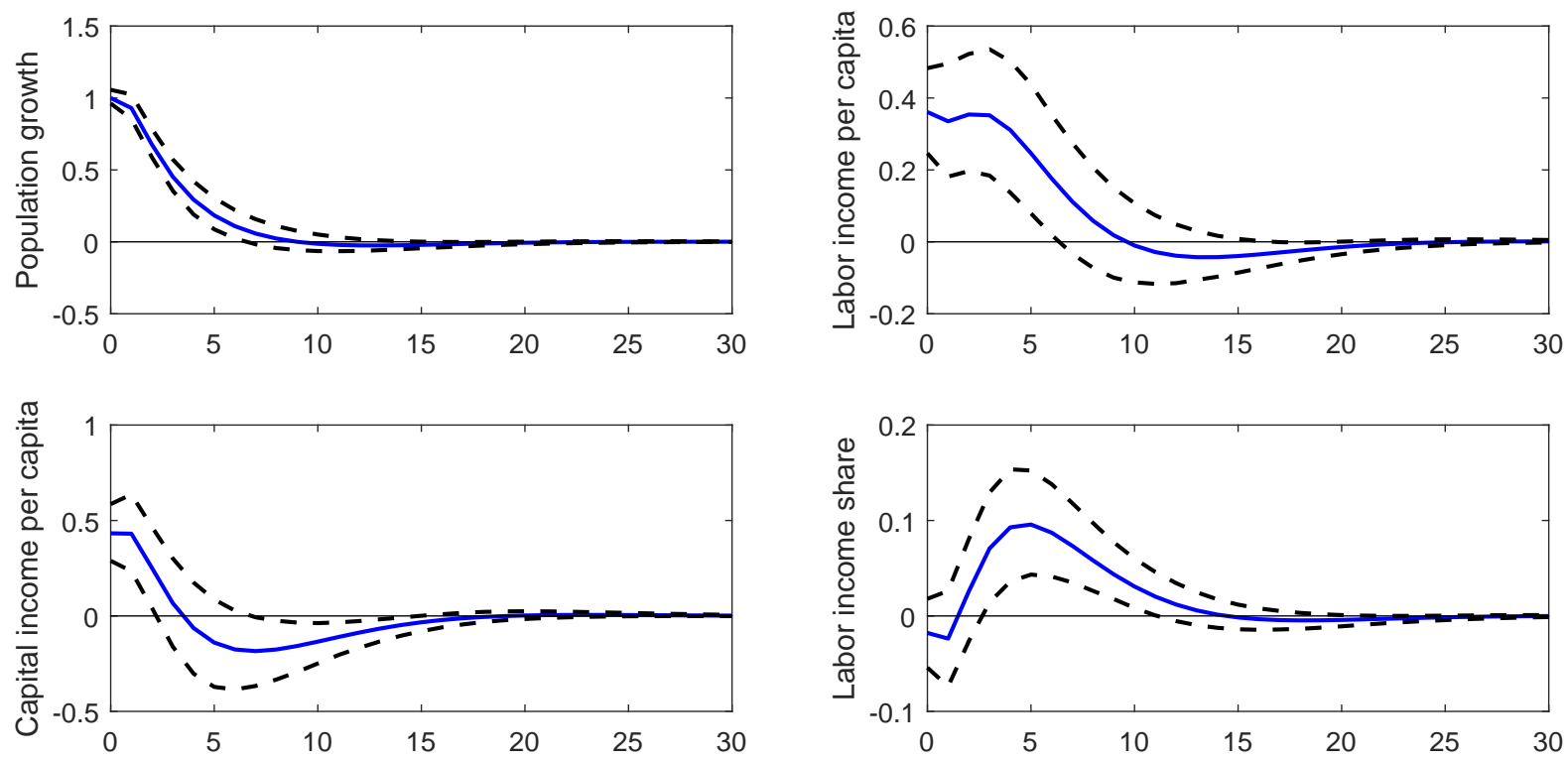

Notes: The solid line gives the estimated impulse response. Dashed lines give the $90 \%$ confidence intervals generated by Monte Carlo simulations with 5000 repetitions. The size of shocks is set to 1 per 1,000 inhabitants. The response of population growth is in per 1,000 points change. The responses of per capita economic variables are in percentage change. For the labor income share, the response is in percentage points change.

Table 2: Percentage of the fluctuations attributable population growth shock

\begin{tabular}{lcccccccc}
\hline & Year 0 & Year 1 & Year 2 & Year 5 & Year 10 & Year 15 & Year 20 & Year 30 \\
\hline Rate of population growth & 100.00 & 99.62 & 97.91 & 89.88 & 84.52 & 84.13 & 84.11 & 84.10 \\
Labor income per capita & 4.21 & 4.84 & 5.86 & 7.88 & 7.65 & 7.66 & 7.69 & 7.69 \\
Capital income per capita & 3.85 & 4.68 & 4.35 & 3.71 & 4.60 & 4.79 & 4.79 & 4.79 \\
Total income per capita & 5.70 & 7.02 & 7.33 & 6.64 & 6.32 & 6.47 & 6.49 & 6.49 \\
Labor income share & 0.11 & 0.17 & 0.24 & 3.11 & 5.24 & 5.25 & 5.26 & 5.26 \\
\hline \multicolumn{2}{l}{ Notes: Year 0 stands for the year of the shock. The percentage of fluctuations attributable to a given shock is }
\end{tabular}

Notes: Year 0 stands for the year of the shock. The percentage of fluctuations attributable to a given shock is the forecast error variance of the corresponding variable explained this shock. 
Figure 8: Responses to birth, death and migration shocks
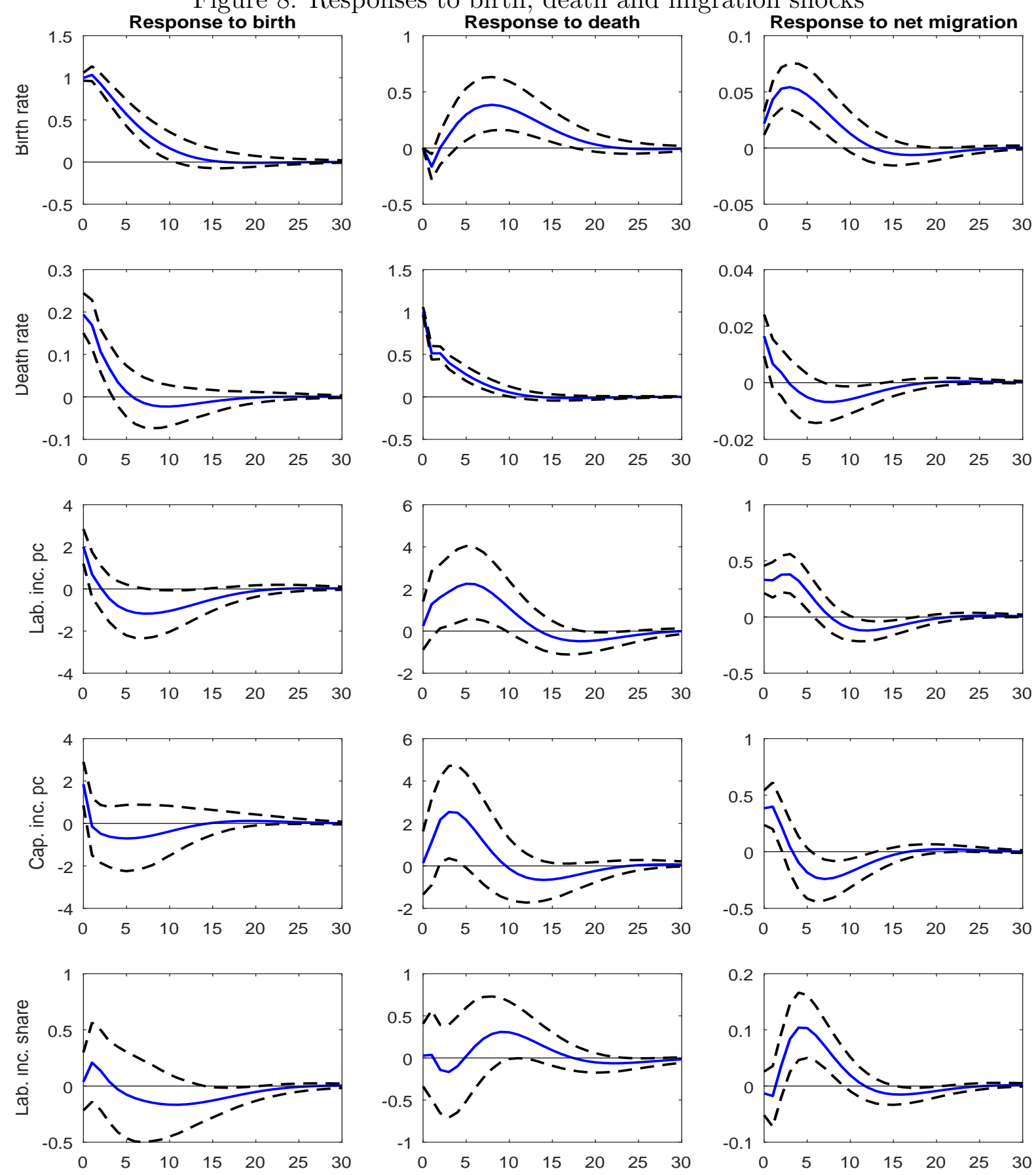

Notes: The solid line gives the estimated impulse response. Dashed lines give the $90 \%$ confidence intervals generated by Monte Carlo simulations with 5000 repetitions. The size of shocks is set to 1 per 1,000 inhabitants. The responses of demographic variables are in per 1,000 points change. The responses of per capita economic variables are in percentage change. For the labor income share, the response is in percentage points change. 
Figure 9: Labor income share and income distribution
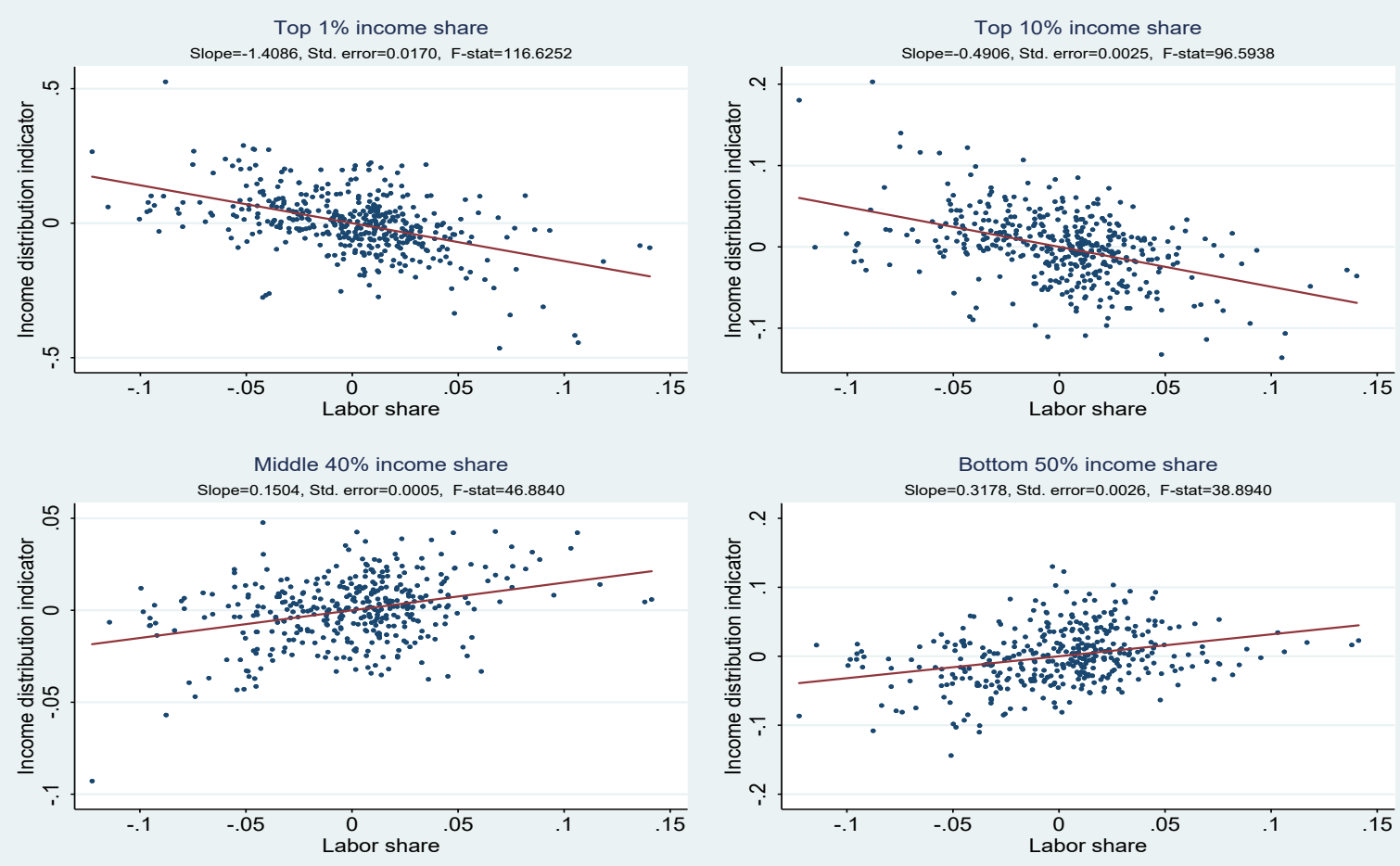

Notes: In figure, the values of labor income share and income distribution indicators are purged of country fixed-effects and year fixed-effects.

Table 3: Granger causality between labor income share and income inequality

\begin{tabular}{|c|c|c|c|c|}
\hline \multirow{2}{*}{$\begin{array}{l}\text { Income } \\
\text { inequality } \\
\text { index }\end{array}$} & \multicolumn{2}{|c|}{$\begin{array}{c}\text { Labor income share } \\
\text { to inequality }\end{array}$} & \multicolumn{2}{|c|}{$\begin{array}{c}\text { Inequality to } \\
\text { Labor income share }\end{array}$} \\
\hline & Test Stat. & P-value & Test Stat. & P-value \\
\hline Top 1\% income share & $4.352^{* * *}$ & 0.000 & -0.377 & 0.706 \\
\hline Top $10 \%$ income share & $3.561^{* * *}$ & 0.000 & -0.875 & 0.382 \\
\hline Middle $40 \%$ income share & $3.644^{* * *}$ & 0.000 & -0.565 & 0.572 \\
\hline Bottom $50 \%$ income share & $1.800^{*}$ & 0.072 & 1.019 & 0.308 \\
\hline
\end{tabular}

Notes: The test statistics is computed based on the cross-sectional Wald statistics and under the null hypothesis of homogenous non-causality it follows the standard normal distribution (with mean equal to 0 and standard deviation equal to 1 ). * and ${ }^{* * *}$ denote statistical significance at 10 and $1 \%$ levels, respectively. 
Figure 10: Income inequality

(a) Top 1\% income share
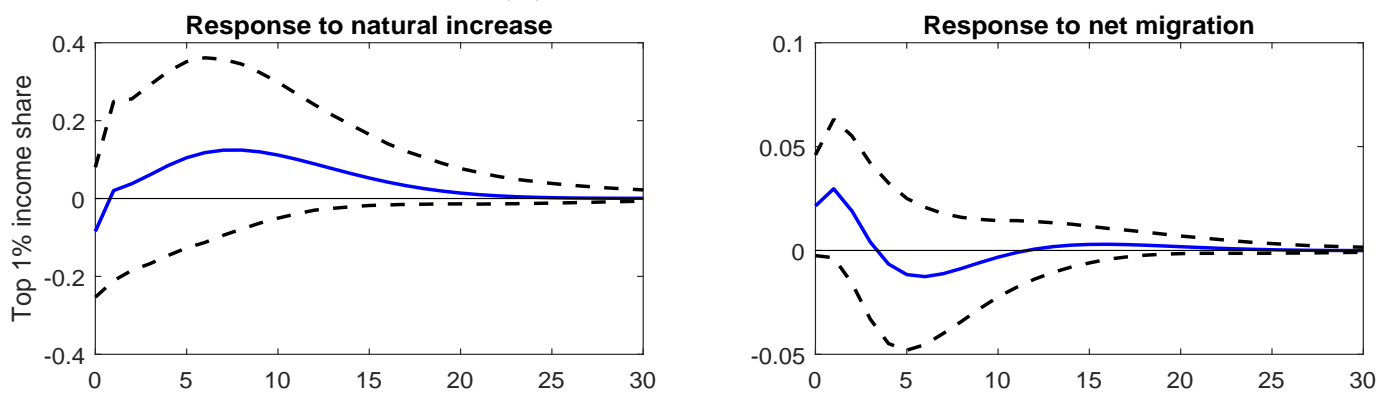

(b) Top $10 \%$ income share
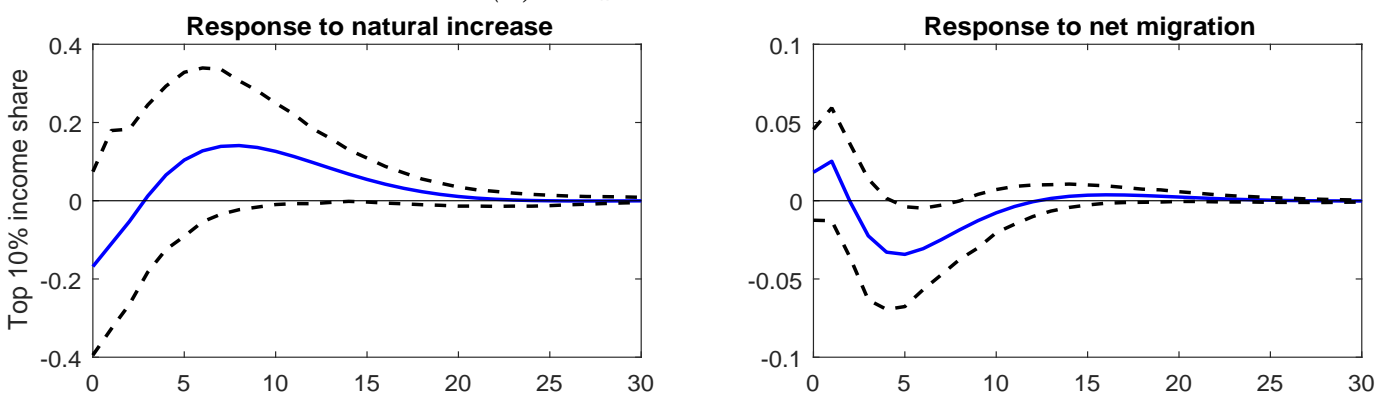

(c) Middle $40 \%$ income share
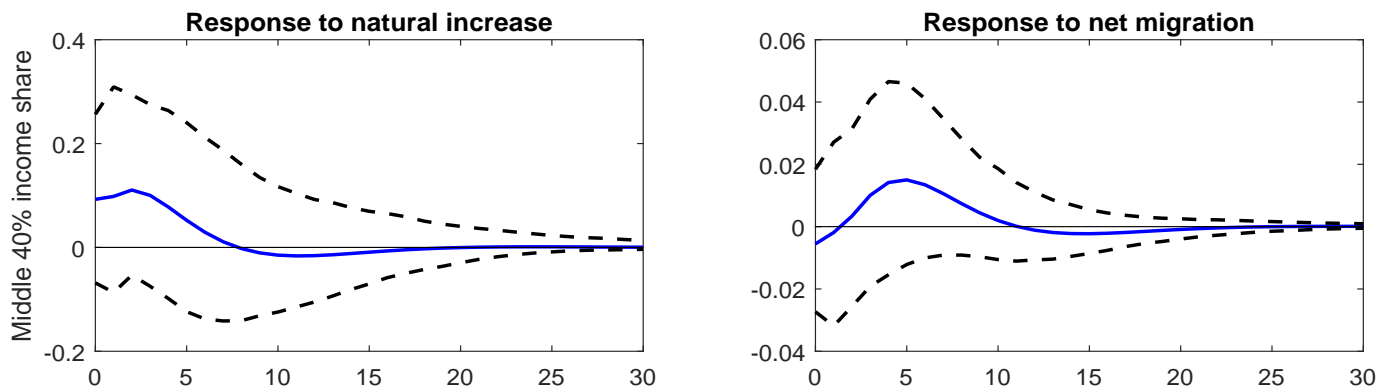

(d) Bottom 50\% income share
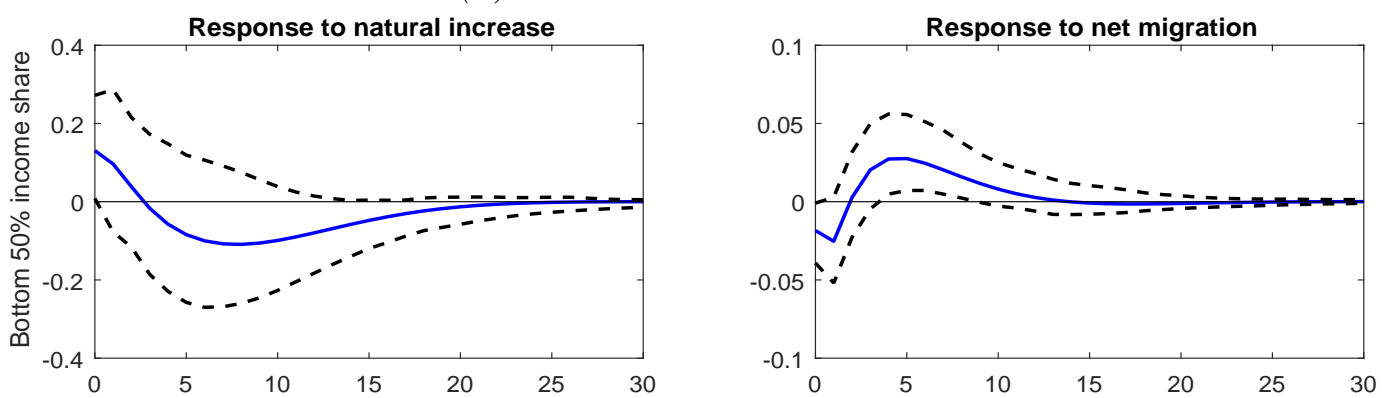

Notes: The solid line gives the estimated impulse response. Dashed lines give the $90 \%$ confidence intervals generated by Monte Carlo simulations with 5000 repetitions. The size of shocks is set to 1 per 1,000 inhabitants. The responses are in percentage points change. 


\section{Funding}

This work was supported by the Agence Nationale de la Recherche of the French government through the program "Investissements d'avenir" ANR-10-LABX-14-01.

\section{Acknowledgments}

We would like to thank the Editor of this journal, Florin Bilbiie, an Associate Editor and a referee for their critics and suggestions. We also thank David Canning, Giorgio Fabbri, David Lam, Murray Leibbrandt and participants at the IUSSP Research Conference on Population, Poverty and Inequality held at the University of Michigan at Ann Arbor for their comments. The usual disclaimer applies.

\section{Appendix}

\section{A.1 Data}

From OECD Economic Outlook database and the OECD Annual Account databases, the economic variables are computed by using the following series codes:

PGDP: Gross domestic product deflator

WSSS: Compensation of employees, current prices

GOS: Gross operating surplus and gross mixed income, current prices

The economic variables of interest in real terms, are computed as follows:

Labor income $=$ WSSS $/$ PGDP

Capital income $=$ GOS/PGDP

Total income $=($ GOS + WSSS $) /$ PGDP

Labor income share $=$ WSSS $/($ GOS + WSSS $)$

To calculate per capita variables, we use the average population.

From OECD Main Economic Indicators database, we use the annual share price index as proxy of stock market index in the robustness analysis to take into account the role of anticipations. Share price index is calculated from the prices of common shares of 
companies traded on national or foreign stock exchanges. Annual data are averages of monthly data which are averages of daily quotations (see OECD, 2020b for more details). Note that share price index is not available for the Portugal before 1988, for Belgium and Norway before 1986.

From the World Inequality database, we consider the following variables:

$\tilde{y}$ : National income average income (per adults) PPP, constant (2017) which include net incomes receivable from the rest of the world, not generated by the production process.

$\tilde{y} P$ : Pre-tax national income share of percentile $\mathrm{P}$, aggregate on population aged over 20.

Note that the percentiles are available for some years only. More precisely, $\tilde{y} 1 p$ (top $1 \%$ income share) and $\tilde{y} 10 p$ (top $10 \%$ income share) data are available over the 19852014 for 14 OECD countries. We exclude Austria (data are available only since 1987), Belgium (data are available only since 1990), Canada (data are available until 2010) and Japan(data are available until 2011). For $\tilde{y} 40 p$ (middle $40 \%$ income share) and $\tilde{y} 50 p$ (bottom 50\% income share) data are available over the 1985-2014 for 13 OECD countries. In addition of the 4 countries mentioned above, we also exclude Australia for which data are not available at all.

\section{A.2 Descriptive statistics}

Table A-1 provides the mean values of our main variables over the period 1985-2018. Economic variables are here expressed at constant PPPs, constant 2015 USD. 
Table A-1: Summary statistics, averages per country over the sample period (1985-2018)

\begin{tabular}{|c|c|c|c|c|c|c|c|}
\hline Country & $\begin{array}{c}\text { Pop. } \\
\text { change } \\
\text { (per } 1,000)\end{array}$ & $\begin{array}{c}\text { Natural } \\
\text { increase } \\
\text { (per } 1,000)\end{array}$ & $\begin{array}{c}\text { Net } \\
\text { migration } \\
\text { (per } 1,000)\end{array}$ & $\begin{array}{c}\text { Total income } \\
\text { per capita } \\
\text { (PPP, } 2015 \text { USD) }\end{array}$ & $\begin{array}{c}\text { Labor income } \\
\text { per capita } \\
\text { (PPP, } 2015 \text { USD) }\end{array}$ & $\begin{array}{c}\text { Capital income } \\
\text { per capita } \\
\text { (PPP, } 2015 \text { USD) }\end{array}$ & $\begin{array}{c}\text { Labor income } \\
\text { share } \\
\text { (in \%) }\end{array}$ \\
\hline Australia & 13.63 & 7.09 & 6.55 & 34679 & 18743 & 15936 & 54.23 \\
\hline Austria & 4.67 & 0.47 & 4.20 & 37686 & 20787 & 16899 & 55.45 \\
\hline Belgium & 4.30 & 1.41 & 2.90 & 35508 & 20068 & 15441 & 56.55 \\
\hline Canada & 10.80 & 4.79 & 6.02 & 33946 & 19444 & 14502 & 57.47 \\
\hline Denmark & 3.76 & 1.08 & 2.69 & 37465 & 22468 & 14998 & 59.96 \\
\hline Finland & 3.54 & 1.85 & 1.70 & 32657 & 18031 & 14627 & 55.59 \\
\hline France & 4.96 & 3.98 & 0.98 & 31576 & 18725 & 12851 & 59.29 \\
\hline Germany & 3.02 & -1.44 & 4.46 & 35860 & 20535 & 15325 & 57.43 \\
\hline Ireland & 9.65 & 7.36 & 2.30 & 39968 & 17275 & 22693 & 45.45 \\
\hline Italy & 1.91 & -0.55 & 2.45 & 32654 & 14493 & 18162 & 44.43 \\
\hline Japan & 0.99 & 1.02 & -0.03 & 33578 & 18157 & 15421 & 54.04 \\
\hline Netherlands & 5.28 & 3.27 & 2.01 & 38970 & 21366 & 17605 & 54.98 \\
\hline Norway & 7.42 & 3.31 & 4.11 & 47054 & 23893 & 23161 & 51.04 \\
\hline Portugal & 0.76 & 0.31 & 0.46 & 23512 & 12487 & 11025 & 53.13 \\
\hline Spain & 5.94 & 1.38 & 4.56 & 28066 & 14625 & 13442 & 52.06 \\
\hline Sweden & 6.03 & 1.60 & 4.43 & 32690 & 18391 & 14299 & 55.98 \\
\hline United Kingdom & 4.89 & 2.34 & 2.55 & 32150 & 17671 & 14480 & 54.80 \\
\hline United States & 9.63 & 5.79 & 3.84 & 44451 & 26082 & 18370 & 58.92 \\
\hline 18 OECD & 5.62 & 2.51 & 3.12 & 35137 & 19069 & 16069 & 54.49 \\
\hline
\end{tabular}

Source: Eurostat (2020) and OECD (2017, 2020a) databases, authors' computations of the main variables. 
Labor income per capita ranges from $\$ 12,486$ for Portugal to $\$ 26,081$ for the United States. The sample averages of capital income per capita range respectively from $\$ 11,025$ in Portugal to $\$ 23,161$ in Norway. Over the period 1985-2018, Denmark recorded the largest labor income share on average, followed by France and the United Stated (60\%, $59.3 \%$ and $58,9 \%$, respectively). The lowest labor income share was recorded in Italy and Ireland $(44,4 \%$ and $45,4 \%$, respectively). Japan has the lowest net migration rate $(-0.03 \%)$, its population growth is driven by the rate of natural increase $(1.02 \%)$. Portugal has a low net migration rate $(0.46 \%)$ and a low rate of natural increase $(0.30 \%)$. The highest net migration rate are recorded in Australia, Canada and Spain (6.55\%, $6.01 \%$ and $4.56 \%$, respectively). Australia and Canada have also a high rate of natural increase (7.08\%oand 4.79\% , respectively). Over the period 1985-2015, Germany and Italy have witnessed an average natural decrease $(-1.44 \%$ and $-0.54 \%$, respectively), that was more than offset by the net migration rate (4.45\% and $2.45 \%$, respectively).

\section{A.3 Additional specifications}

To discuss the effects of demographic shocks, we consider the following specifications in addition to the baseline specification presented in subsection 2.2 :

$$
\begin{aligned}
X_{i t}^{2} & =\left[\log \left(1+m_{i t}\right), \log \left(1+n_{i t}\right), \log \left(w_{i t}\right), \log \left(r_{i t}\right), \log \left(u_{i t}\right)\right]^{\prime}, \\
X_{i t}^{3} & =\left[\log \left(1+p c_{i t}\right), \log \left(w_{i t}\right), \log \left(r_{i t}\right)\right]^{\prime}, \\
X_{i t}^{4} & =\left[\log \left(1+m_{i t}\right), \log \left(b_{i t}\right), \log \left(d_{i t}\right), \log \left(w_{i t}\right), \log \left(r_{i t}\right)\right]^{\prime}, \\
X_{i t}^{5} & =\left[\log \left(1+m_{i t}\right), \log \left(1+n_{i t}\right), \log \left(\tilde{y}_{i t}\right), \log \left(\tilde{y} 1 p_{i t}\right)\right]^{\prime}, \\
X_{i t}^{6} & =\left[\log \left(1+m_{i t}\right), \log \left(1+n_{i t}\right), \log \left(\tilde{y}_{i t}\right), \log \left(\tilde{y} 10 p_{i t}\right)\right]^{\prime}, \\
X_{i t}^{7} & =\left[\log \left(1+m_{i t}\right), \log \left(1+n_{i t}\right), \log \left(\tilde{y}_{i t}\right), \log \left(\tilde{y} 40 p_{i t}\right)\right]^{\prime}, \\
X_{i t}^{8} & =\left[\log \left(1+m_{i t}\right), \log \left(1+n_{i t}\right), \log \left(\tilde{y}_{i t}\right), \log \left(\tilde{y} 50 p_{i t}\right)\right]^{\prime} .
\end{aligned}
$$

where : $m, n$ and $p c$ are respectively the net migration, natural increase and total population growth, expressed as a share of the population on 1 January. We add one to express 
these variables in logarithm to handle with negative values. Moreover, $w$ and $r$ are labor income per capita and capital income per capita, respectively; $u$ is the unemployment rate; $b$ and $d$ are the live births and deaths as a share of the population on 1 January, respectively; $\tilde{y}, \tilde{y} 1 p, \tilde{y} 10 p, \tilde{y} 40 p$ and $\tilde{y} 50 p$ are: the average national income, the share of the $1 \%$ of people with highest pre-tax national income, the share of the $10 \%$ of people with highest pre-tax national income, the share of the $40 \%$ of people with the middle pretax national income, and the share of the $50 \%$ with the bottom pre-tax national income, respectively.

It is worth recalling that demographic variables are ordered first in the Choleski decomposition for the reasons presented and discussed in the paper for the baseline specification. Note that we check the sensitivity of our results to alternative ordering between net migration and natural increase in the Choleski decomposition. Even, it would be very unlikely that a shock rising the rate of natural increase would influence the net migration rate during the year of the shock, we place the rate of natural increase before net migration rate and leave the ordering of the other variables unaltered. The impulse response to natural increase and migration shocks for this alternative ordering are similar to the results reported Figure $3^{8}$.

\footnotetext{
${ }^{8}$ The estimation using the alternative ordering is available upon request to the authors.
} 